\title{
Benefit transfer of climate change adaptation policies in island tourist destinations
}

\author{
Yen E. Lam-González ${ }^{\text {a, }}$, Carmen García ${ }^{\text {a }}$, Matías M. González Hernández ${ }^{\text {a }}$, Carmelo J. León ${ }^{\text {a }}$ \\ ${ }^{\text {a }}$ Institute of Tourism and Sustainable Economic Development, University of Las Palmas de Gran Canaria, Campus de Tafira, 35017, Spain
}

\section{A R T I C L E I N F O}

\section{Keywords:}

Benefit transfer

Climate change

Adaptation policy

Discrete choice experiments

Tourism management

\begin{abstract}
A B S T R A C T
Benefit transfer is a non-market valuation method that offers a quick and cost effective alternative to costly valuation methods for assessing the economic value of environmental goods and policies in tourism. This paper assesses the validity of the benefits transfer method for the policies to adapt to climate change impacts across tourist destinations. To do so, a discrete choice experiment is designed and conducted simultaneously across seven island destinations with similar sociological and environmental characteristics. The results show some climate change adaptation policies are more valued than others by tourists, and some destinations attract higher preferences for environmental actions. The tests give significant support to the validity of the transfer of benefits of adaptation policies across destinations, thereby providing an alternative for the economic assessment of the benefits of non-market goods and climate change adaptation policies in tourism, as worldwide information about the costs and benefits involved in tourism policy decision making become increasingly available.
\end{abstract}

\section{Introduction}

The tourism industry is subject to potential impacts of global climate change that are likely to have significant economic effects because tourist demand may react to the changes in the environmental attributes of tourist destinations (Gössling et al., 2012; Scott, Hall, \& Gössling, 2012; Scott \& Lemieux, 2012; Atzori et al., 2018). That is, as the impacts of climate change are experienced at destinations, tourists may change their behaviour and opt for alternative destinations with lower risks (Hall et al., 2012; Nilsson \& Gössling, 2013). For instance, tourists are sensitive to heat waves and extreme temperatures at destinations (Rutty \& Scott, 2010), as well as to melting glaciers (Heron et al., 2017), beach degradation and tropical diseases (Atzori et al., 2018), higher risks of forest fires (Amelung \& Nicholls, 2014; Arabadzhyan et al., 2020), among other valued resources that may be affected such as ecosystems services of flag species (whales, dolphins or birds) and the idiosyncratic natural features of coastal areas (Kaján \& Saarinen, 2013; Kaján et al., 2015).

The study of the impacts of climate change at tourist destinations is also relevant in order to decide upon the most efficient policy measures that should be undertaken in order to prevent the expected socioeconomic damages and losses (Buzinde et al., 2010; Rulleau \& Rey-Valette, 2013). This paper analyses the most relevant impacts of climate change in island tourism destinations and the associated adaptation policies (Arabadzhyan et al., 2020; Scott et al., 2019). Island destinations are likely to be most affected because of their long coastal areas and large endowments of marine and terrestrial ecosystems, and because most of them focus on tourism as their most important economic activity (Cashman et al., 2012; Scott et al., 2019; Susanto et al., 2020). The research question is to what extent there is scope for the application of the benefit transfer methodology for assessing the economic value of climate change adaptation policies across tourist destinations. In this vein, the importance of this research lies on the fact that the tourism sector and the tourism academy lack capacity to provide the massive information required to promote fast and smart adaptation to climate change. (Scott, 2021).

Benefit transfer is a method for assessing the potential economic value of environmental impacts utilizing research from pre-existing studies for which estimates are available (Johnston et al., 2015; Smith, 1992). That is, values or data from a "study site" are available or collected to be applied or transferred to a "policy site" where no data is available. The benefit transfer method has been utilized in many applications to assess the costs and benefits related with environmental impacts and policies (Johnston \& Rosenberger, 2010; Rosenberger \& Loomis, 2003). Its origins are in the 1980s, although is not until the 1990s that the method became scientifically formalized and supported

\footnotetext{
* Corresponding author.

E-mail address: yen.lam@ulpgc.es (Y.E. Lam-González).
} 
by academic scholars, becoming the most applied method in the context of benefit cost analysis (Boyle \& Bergstrom, 1992; Brookshire \& Neill, 1992).

The principal advantage of benefit transfer is that it reduces the costs of time and money that are needed to assess the benefits of environmental policies utilizing other non-market valuation methods (Johnston et al., 2021). Kaul et al. (2013) showed that the accuracy of benefit transfer differs depending on the type of economic valuation method on which the transfer is supported. In the 1990s most applications of benefit transfer were based on the contingent valuation method (CVM), although in the last two decades there has been some attempts to explore the accuracy of benefit transfer for the discrete choice experiments (DCE) method (Andreopoulos \& Damigos, 2017; Brouwer et al., 2015; Colombo et al., 2007; Johnston \& Duke, 2010; Morrison et al., 2002), also within the tourism literature with details provided later. Authors have advocated the advantages of DCE for benefit transfer because it provides more detailed descriptions of the goods to be valued allowing for the valuation of multiple attributes, and therefore enabling a closer adjustment to the specific characteristics and scenarios of the policy sites and the policy proposals (Johnston et al., 2021).

DCE is an attribute-based valuation method that consists of asking tourists to choose between alternative profiles defined by different combinations of policy measures or environmental impacts (Hoyos, 2010; Mariel et al., 2021, p. 129). This method has become very popular in the evaluation of tourists' preferences and economic values in both natural areas and other policy destination settings (Eymann \& Ronning, 1997; Huybers, 2003; Kemperman, 2021; Morley, 1994).

This paper utilizes DCE for the evaluation of climate change policies at island destinations and tests the validity of the transfer method across a set of islands in the Mediterranean and Atlantic regions. The validity and reliability of the benefit transfer method have not been earlier assessed in the context of tourist policies. Therefore, the paper fills a research gap in the area of environmental valuation in tourism by exploring the prospects of conducting benefit transfer analysis. The development of this area of research could enable tourist destinations to have available more efficient alternatives to assess the economic benefits of environmental policies and natural resources.

The paper is structured as follows. Section 2 presents a review of the relevant literature related to climate change impacts and the utilization of DCE in the valuation of natural assets in tourism. Section 3 outlines the research methods utilized for benefit transfer and section 4 describes the data collection procedure. Section 5 presents the results of the DCE data analysis and benefit transfer testing procedures. Finally, Section 6 discusses the results while Section 7 summarizes the main conclusions and implications of the study.

\section{Literature review}

\subsection{Valuation of the environment with DCE in tourism}

The tourism industry utilizes a large amount of natural and environmental assets in the production of services offered to tourists (Holden, 2016; Tang, 2015). This has prompted tourism scholars to apply non-market valuation techniques for the assessment of natural resources and environmental policies. In the last decades, DCE have become one of the most popular methods overcoming CVM (contigent valuation methods) as the most applied non-market valuation approach (Kemperman, 2021; Kim \& Park, 2017).

The applications of DCE in tourism have paid much interest to natural areas and ecotourism activities. For instance, Chaminuka et al. (2012) focused on tourists' preferences for ecotourism in rural communities while Olmsted et al. (2020) assessed the support of conservation programs in ecotourism. There are also a number of applications intended to elicit the willingness to pay of tourists for the attributes related to the management of the ecosystems and congestion in natural areas (Dumitras, 2017; Leon et al., 2015; Naidoo et al., 2021). Enríquez and Bestard (2020) applied DCE to evaluate the economic impacts of climate change on some of the marine and coastal features enjoyed by tourists, in particular, those caused by beach retreat, jelly fish outbreaks and ecosystems deterioration.

The preferences of tourists for the observation of wildlife species, such as marine mammals and birds have been also the object of significant research utilizing DCE (Bach \& Burton, 2017; Kubo et al., 2019; Lee et al., 2010; Malpica-Cruz et al., 2017). Further, DCE have also helped scholars to elicit tourists' preferences for climate change policies such as carbon neutral schemes in aviation (Choi \& Ritchie, 2014), the value of specific adaptation measures in key tourist sectors such as skiing tourism (Landauer et al., 2012), and the change of destination because of climate change at tourist destinations (Seekamp et al., 2019). Linked to the assessment of externalities in the transportation system, some efforts have been paid to the preferences for transportation modes and policies (Hergesell \& Dickinger, 2013) and the assessment of the tourism-traffic paradox in mountain destinations (Scuttari et al., 2019).

Although not directly related to environmental resources, the potential preferences of tourists for better management of cultural heritage, and the value raised by heritage attributes to their travel experiences, have also received the attention of DCE researchers. For instance, Choi et al. (2010) studied the economic value of cultural sites, while Lacher et al. (2013) focused on the role of heritage and cultural elements in the preferences for coastal tourism.

\subsection{Impacts of climate change in island tourist destinations}

Tourism is going to be importantly affected by climate change because it is expected to affect the environmental attributes that attract tourists to destinations. The particular impacts are going to depend on the type of destination, with those placed along coastal areas being specifically affected by the sea level rise and the damages to marine ecosystems (Arabadzhyan et al., 2020), including cultural heritage assets (Reimann et al., 2018). These impacts are likely to affect both the supply and demand of tourism.

For instance, climate change may erode coastal areas and reduce beach spaces, making tourists less willing to return or to change the decision to travel to those destinations that are affected (Raybould, 2013). However, there is compelling evidence that restoration policies are valued by tourists making them to favourably reconsider their traveling decisions (Koutrakis et al., 2011; Rulleau \& Rey-Valette, 2013; Kontogianni et al., 2014; Enríquez and Bestard, 2020). In this vein, Buzinde et al. (2010) have proven that beach nourishment has dual impact on visitors, at the level of the image enhancement and in shaping perceptions of space. With the benefits of beach restoration measures being understood by almost all, the problem of many SIDS and outermost regions is their inability to afford the major costs associated with structural protection and beach nourishment, and to access to environmentally sustainable sources of sand (Scott, Simpson, \& Sim, 2012).

Many tourist destinations also depend on the quality of their biodiversity of marine and land environments, which may be affected by climate change (Arabadzhyan et al., 2020; Scott \& Lemieux, 2012). Evidence shows that tourists react negatively to the increase of jellyfish populations in coastal areas (Nunes et al., 2015; Enríquez and Bestard, 2020), while the degradation of coral reefs and ecosystems reduces the quality of the amenities tourists enjoy at destinations (Verkoeyen \& Nepal, 2019; Nilsson \& Gössling, 2013). Likewise, the reduction of the stocks of flag species such as turtles or whales, may lead to changes in traveling decisions and to a reduction of the economic potential of their related activities (Poloczanska et al., 2009; Gössling et al., 2012). Tourists' economic values for restoration policies of ecosystem services have also been demonstrated to be significant e.g. in the cases of coral reefs (Rolfe \& Windle, 2012; Tseng et al., 2015; McClenachan et al., 2018) and coastal and marine conservation (Schuhmann et al., 2019; Enríquez and Bestard, 2020).

Tourists are also sensitive to the rise in temperature and possible 
extreme weather events, since the weather is the most important variable in traveling decisions (Rutty et al., 2020; Scott et al., 2008; Scott \& Becken, 2010). Thus, there can be changes in the flow of tourists to destinations (Gómez-Martín et al., 2014) i.e. some destinations may become less attractive because of the frequency of heat waves in the summer season while other destinations may be favoured because of more pleasant weather conditions (Rutty \& Scott, 2010). Cavallaro et al. (2017) found that climate change will impact the type of activities tourists can carry out thereby having an effect on the seasonality of the flow of tourists to some destinations (Mattheus et al., 2021; Rutty et al., 2020).

The environmental risks caused by more probable wildfires and infectious diseases at destinations are also likely to affect tourists' flows and decisions. There is some evidence that the number of tourist arrivals is reduced after forest fires (Otrachshenko \& Nunes, 2019), although in Florida, where fires are quite frequent, the evidence is that they do not discourage tourists from visiting the destination (Thapa et al., 2013). However, Bonnieux et al. (2006) and Kountouris and Remoundou (2011) found that tourists value and are willing to pay for fire prevention programs that reduce the risks of wildfires. In respect of the risks of infectious diseases, there is not much evidence of how they may affect current popular tourist destinations. Existing literature on the physical impacts often suggests an increase in the spread of various diseases such as dengue and malaria, caused primarily by higher temperatures, though the impacts may differ depending on the exact region, the tourism segment or vector under study (Liu \& Pennington-Gray, 2017; Ryan et al., 2019). Available studies have indicated that potential outbreaks of unknown vector-borne diseases may have lasting impacts on the attractiveness of destinations with potential economic losses in terms of tourist revenues and Gross Domestic Product (Mavalankar et al., 2009; Panzer \& Saavedra, 2016).

\section{Methods}

Benefit transfer of climate change policies can be performed utilizing a unit value or a value function transfer (Johnston et al., 2015; Loomis, 1992). The unit value approach consists of applying to the policy site the mean value of the same policies obtained at the study sites. The value transfer method is a predictive approach that involves the application of the valuation function obtained for the study site to the policy site, adjusting for the socioeconomic characteristics of the policy site (Johnston et al., 2015). A valuation function is a function that relates individuals' willingness to pay (WTP) -or utility values-to the socioeconomic characteristics and attributes of the study or policy sites. There are other approaches to benefit transfer that involve meta-analytic data and methods and the incorporation of expert opinion (Johnston et al., 2021; Rosenberger \& Loomis, 2003).

In this paper, the value function transfer approach is tested utilizing data from a DCE on the value that tourists place on climate change adaptation policies (Brouwer et al., 2015; Andreopoulos \& Damigos, 2017). Let the utility of the individual $i$ from choosing alternative $j$ involving a climate change policy option be composed of the summation of a deterministic part and a random part, i.e. $U_{i j}=X_{i j} \beta_{i}+\varepsilon_{i j}$, where $X_{i j}$ is a vector of climate change policy options and a constant term or alternative specific constant (ASC); $\beta_{\mathrm{i}}$ is a vector of parameters which can be also formed by the combination of a fixed or deterministic part $\delta_{i}$ and a random term $\gamma_{\mathrm{i}}$ i.e. $\beta_{\mathrm{i}}=\delta_{\mathrm{i}}+\gamma_{\mathrm{i}}$ as in the mixed Logit or random parameter model (Colombo et al., 2007; Kim \& Park, 2017; Mariel et al., 2021, p. 129). In DCE, the probability that the individual chooses a climate change policy option $j$ over any alternative $h$ is $\mathrm{P}\left(\mathrm{U}_{\mathrm{j}}<\mathrm{U}_{\mathrm{h}}\right) \forall h \neq j$, or more precisely:

$P_{i j}=\int \frac{\exp \left(X_{i} \beta\right)}{\sum_{h} \exp \left(X_{i h} \beta\right)} f(\beta) d \beta$

The estimated parameters allow to assess monetary welfare measures or implicit prices for the different climate change policies $V_{t}$ by evaluating the ratio between the estimated policy and cost parameters i.e. $\mathrm{V}_{\mathrm{t}}$ $=\beta^{*} t / \beta^{*}$. The socioeconomic characteristics of the respondents as well as the policy characteristics do explain the choice of alternatives and can influence economic values. These respondents' characteristics (S) can be incorporated as interacting with the alternative specific constant (ASC) i.e. with the constant parameter, and/or with the climate change adaptation policy attributes defined in the DCE $\left(\mathrm{X}_{\mathrm{ij}}\right)$.

Thus, the estimated parameter vector $\beta^{*}$ lead to an estimated utility function $U_{s} *\left(\beta_{s}^{*}\left(S_{s}\right)\right)$ for the study site that can be utilized for assessing the benefits of the policy site, where $\beta_{s}{ }^{*}$ is a vector of parameter estimates for the study site and $S_{S}$ is a vector of socioeconomic characteristics of the study site. Value function benefit transfer involves utilizing the estimated utility function for the study site $U_{s}{ }^{*}\left(\beta_{s}{ }^{*}\left(S_{s}\right)\right)$ to assess utility function of the policy site by introducing the parameter vector of the study site and the socioeconomic characteristics of the policy site, $i$. e. $U_{p} *\left(\beta_{s}^{*}\left(S_{p}\right)\right)$, where $S_{p}$ are the socioeconomic characteristics of the policy site. This allows to obtain the estimated economic values of the policy site as $\mathrm{V}^{*}{ }_{\mathrm{tp}}=\beta^{*}{ }_{\mathrm{t}}\left(\mathrm{S}_{\mathrm{p}}\right) / \beta^{{ }^{*}}{ }_{\mathrm{c}}\left(\mathrm{S}_{\mathrm{p}}\right)$.

Benefit transfer can lead to errors in the assessment of the economic values of the climate change measures at the policy site (Brouwer et al., 2015, 2016; Krinsky \& Robb, 1986). Transfer errors are defined as the percent difference between the economic values of the study site and policy sites, i.e. $\left(\left(\mathrm{V}_{\mathrm{tp}}-\mathrm{V}_{\mathrm{ts}}\right) / \mathrm{V}_{\mathrm{tp}}\right) \times 100$ where $\mathrm{V}_{\mathrm{ts}}$ is the assessed economic value at the study site for each specific climate change policy action $t$. Transfer errors may arise because of the potential differences between the expected results based on available information and those that would come out from the actual economic evaluation of climate change policies. Transfer errors can be reduced i) utilizing a value function transfer rather than a unit transfer approach, ii) modelling sample heterogeneity in the value transfer, and iii) considering the appropriate functional form for the value transfer (Johnston \& Duke, 2010; Johnston et al., 2015). Existing studies conclude that $30 \%$ of transfer error can be accepted for empirical works, although it depends on policy-maker demands for accurate estimates (Andreopoulos \& Damigos, 2017; Brouwer et al., 2015, 2016; Colombo et al., 2007).

There are two alternative approaches to test for the accuracy of value function transfer method (Kristofersson \& Navrud, 2005; Morrison et al., 2002). The first looks at the differences between the valuation functions of the policy and study sites, i.e. $U_{p} *\left(\beta_{p} *\left(S_{p}\right)\right)$ and $U_{p} *\left(\beta_{s}^{*}\left(S_{p}\right)\right.$. That is, the question is to what extent the estimated parameters obtained with the study sites can be utilized to predict the values that would be obtained with a sample in the policy site. This involves testing for the equality of the parameters of the transferred value function and the policy site value function. Swait and Louviere (1993) show that when comparing model parameters from discrete choice models of different data sets the scale parameter can vary between data sets leading to changes in the estimated parameters.

In order to isolate the effect of the explanatory variables from the changes in the scale parameter, Swait and Louviere (1993) propose a two steps procedure (S-L test). In a first step the models for both the study and policy sites are estimated and their log likelihood function values and parameter vectors are obtained for each sample. In the second step the two data sets (policy and study sites) are staked together with the scale parameter of the study site data fixed to one and the scale parameter of the policy site data rescaled by some hypothesized value. The scale parameter for the policy site data that maximizes the log likelihood is chosen for the joint or staked model utilizing a grid search simulation. Thus, the equivalence of the estimated parameters between the two data sets $\left(\beta_{\mathrm{p}}^{*}\right.$ and $\left.\beta_{\mathrm{s}}{ }^{*}\right)$ is tested utilizing a log likelihood ratio test, i.e. $L R=-2\left[L_{j}-\left(L_{s}+L_{p}\right)\right]$ where $L_{j}$ is the log-likelihood value of the joint or stacked model and $L_{s}, L_{p}$ are the log-likelihood values of the study and policy sites respectively. This statistic is distributed as a chi-squared distribution with $\mathrm{h}+1$ degrees of freedom, where $\mathrm{h}$ is the number of parameters in the models.

The second approach to test for benefit transfer looks at the statistical 
differences between the economic values or implicit prices obtained with the policy and study sites, i.e. $\mathrm{V}^{*}$ ts and $\mathrm{V}^{*}$ tp. In this approach two complementary tests are performed. The Poe et al. (1994) test is a convoluted approach that proceeds by simulating the welfare distributions utilizing the Krinsky and Robb (1986) resampling method and calculating the difference between those simulated distributions to perform a one-sided significance test statistic.

The Poe test may raise the Type II error on the null hypothesis, i.e. the probability that the hypothesis of equality of the transferred and policy site values is not rejected given that it is false. As a fairer testing alternative, Kristofersson and Navrud (2005) proposed the TOST (or equivalence test) that proceeds by inverting the hypotheses to be tested. That is, in the TOST test the null hypothesis is defined as the difference between the transferred and policy site values $\varphi=\left(\mathrm{V}^{*}{ }_{\mathrm{tp}}-\mathrm{V}^{*}{ }_{\mathrm{ts}}\right)$ to be higher than a certain threshold or tolerance level $\Theta$, e.g. $20 \%$. The null hypothesis is defined as $\mathrm{H}_{0}: \varphi \leq-\Theta$ or $\varphi \geq \Theta$, while the alternative hypothesis is $\mathrm{H}_{1}:-\Theta<\varphi<\Theta$. Thus, this test introduces certain flexibility in the differences between the transferred and study site values allowing for some transferred errors to be acceptable in statistical terms. The test is performed by conducting a two one-sided t-tests based on the statistics $\tau=|(\varphi-\Theta) / \sigma| \geq \tau(1-\alpha)$, where $\tau(1-\alpha)$ is the t-value for $\alpha$ significance level and $\sigma$ is the standard deviation of the difference. The rejection of the null hypothesis involves that under the assumed acceptable transfer error or tolerance level, the transferred and the policy site values are not different from each other.

\section{Data}

The data focuses on assessing the economic value of policies against the impacts of climate change in island tourist destinations. The impacts and the adaptation policies were defined with the help of a group of experts who were invited to participate in the study. In total, fifty highlevel representatives of the tourism industry, policy makers, academy and other coastal sectors (fisheries, maritime transport, energy, climate) participated in this qualitative stage of the research. This work was supported by the European Union's Horizon 2020 research and innovation program, with the European Commission and the project partners of the action being the bridge to articulate a great network of experts and

Table 1

Summary of the climate change impacts and adaptation policies utilized in the choice experiments.

Climate change impacts

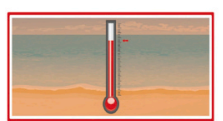

Decreased Thermal Comfort

More frequent periods of several days or weeks of excessive hot weather.

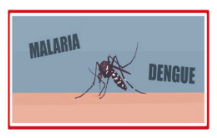

\section{Infectious Diseases}

Increased risk of malaria and dengue, which are transported by mosquitos that manage to survive under the new climatic conditions

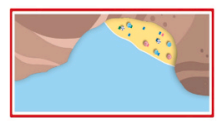

Beach reduction

Sandy beaches partially disappear because of sea level rise and the increase of storms.

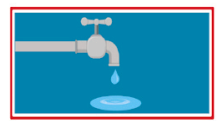

Water scarcity

Many areas will present water shortages and scarcity, facing droughts.

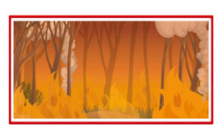

\section{Forest Fires}

Increased number and effects of forest fires fuelled by warmer climatic conditions and droughts.

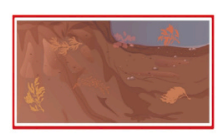

\section{Degradation of marine habitats}

Reduced diversity and abundance of endemic, flagship and exotic species, and increased death algae and plants.

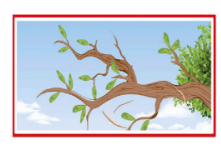

Degradation of land environments Animal and plants are affected due to the rising temperatures and the increase in water shortages.

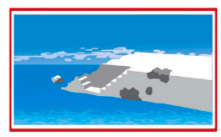

Damages to coastal Infrastructures and facilities

Strong weather patterns will damage transport infrastructures, energy generation plants, and education and health facilities

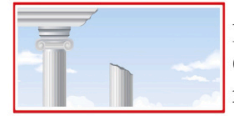

Damages to Cultural Heritage

Cultural heritage is affected by sea level rise, storms, floods and landslides.
Adaptation programs

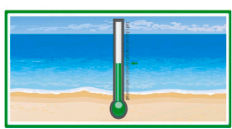

Heat Waves Amelioration (HEAT)

Early warning, proper information for vulnerable groups, air conditioning in public indoor and outdoor places, more green and watered areas.

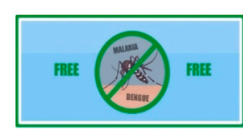

Infectious diseases Prevention (DISEASE)

Proper information and advisement to face outbreaks, fumigation of mosquitoes' prone areas, and emergency medical care plans.

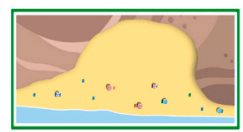

Beaches Protection (BEACH)

Building seawalls and breakwaters, nourishment of sandy beaches and building compensatory artificial beaches across coastal areas.

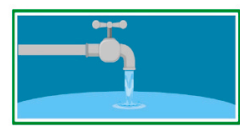

\section{Water Supply (WATER)}

Desalination plants and water facilities reinforcement to guarantee fresh water supply.

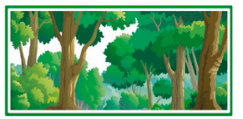

Forest Fires Prevention (FOREST)

Improved forest management to reduce combustibility; increased firefighting technical and human resources, and recovery plans.

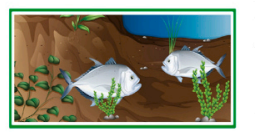

Marine Habitats Restoration (MARINE-H)

To remove dead seagrass, offer marine biodiversity facilities and provide accurate information on best places for each marine activity.

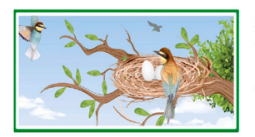

Land Habitats Restoration (LAND-H)

Reforestation and landscape restoration, enhancing protected areas and encouraging botanic gardens and wildlife show places.

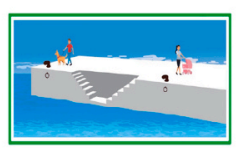

Coastal Infrastructures Protection (COASTAL)

To provide proper information on prevention, and emergency facilities; reinforce coastal structures; and facilitate access to safe places and attractions.

Cultural Heritage Protection (CULTURE)

To reinforce protection of exposed heritage and relocate the endangered cultural assets. 
stakeholders of several EU country members. Two focus groups meetings were organized in each of the seven study sites with the help of the local partners. The meetings served to discuss and validate a set of climate change risks and related policies that are considered a priority concern for these islands.

The process ended on June 2019 (six months' duration), stressing that there are nine specific measurable climate risks that can potentially affect the sustainability of tourism in the islands, although not all islands will be affected equally. Consequently, there is a concern within the tourism policy to accelerate the implementation of specific measures in the medium term, to ensure a more resilient tourism industry. Nine possible adaptation measures were proposed and validated by the stakeholders using four criteria; viability of technical application, costefficiency, potential to enhance the tourist experience, and social benefit. This nine adaptation programs were included in the choice experiment with tourists.

Results of the consultation process were coherent with existing studies. According to estimates, the future of tourism for the EU islands may be fundamentally affected by sea level rise and beach reduction, increased forest fire danger, and prolonged droughts and heat waves leading to water scarcity, decreased thermal comfort and increased suitability of vector borne diseases (Arabadzhyan et al., 2020; Scott et al., 2019). Table 1 presents a description of the nine chosen impacts and adaptation programs that were utilized in the choice experiments. To facilitate the choice experiment, each policy proposal addresses one of the climate change impacts identified for the tourism sector in EU islands.

Each adaptation program has two levels: whether the policy is implemented or not in the tourist destination. In addition to the nine adaptation programs, the price was also considered in the choice experiment. This way, tourists' choices can be analyzed to estimate the contribution of each policy level to their overall utility, and easily be converted into willingness to pay estimates for changes in the policy levels. The choice experiment also proposes that the socio-demographic profile of tourists determines their preferences for adaptation policies. Table 2 presents a description of the variables utilized in the choice experiment.

The questionnaire was the research instrument utilized to elicit the

Table 2

Description of the policy and socioeconomic variables utilized in the choice models.

\begin{tabular}{|c|c|}
\hline Variables & Measurement \\
\hline PRICE & $\begin{array}{l}\text { Continuous variable: } 0 € \text { (no policy); } 1 € ; 3 € ; 5 € ; 7 € \\
\text { Price per day per person. }\end{array}$ \\
\hline $\begin{array}{l}\text { Heat Waves Amelioration } \\
\text { (HEAT) }\end{array}$ & $\begin{array}{l}\text { Dummy variable. It takes value } 1 \text { if the policy is } \\
\text { chosen and zero otherwise }\end{array}$ \\
\hline $\begin{array}{l}\text { Infectious diseases Prevention } \\
\text { (DISEASE) }\end{array}$ & $\begin{array}{l}\text { Dummy variable. It takes value } 1 \text { if the policy is } \\
\text { chosen and zero otherwise }\end{array}$ \\
\hline Beaches Protection (BEACH) & $\begin{array}{l}\text { Dummy variable. It takes value } 1 \text { if the policy is } \\
\text { chosen and zero otherwise }\end{array}$ \\
\hline Water Supply (WATER) & $\begin{array}{l}\text { Dummy variable. It takes value } 1 \text { if the policy is } \\
\text { chosen and zero otherwise }\end{array}$ \\
\hline $\begin{array}{l}\text { Forest Fires Prevention } \\
\text { (FOREST) }\end{array}$ & $\begin{array}{l}\text { Dummy variable. It takes value } 1 \text { if the policy is } \\
\text { chosen and zero otherwise }\end{array}$ \\
\hline $\begin{array}{l}\text { Marine Habitats Restoration } \\
\text { (MARINE-H) }\end{array}$ & $\begin{array}{l}\text { Dummy variable. It takes value } 1 \text { if the policy is } \\
\text { chosen and zero otherwise }\end{array}$ \\
\hline $\begin{array}{l}\text { Land Habitats Restoration } \\
\text { (LAND-H) }\end{array}$ & $\begin{array}{l}\text { Dummy variable. It takes value } 1 \text { if the policy is } \\
\text { chosen and zero otherwise }\end{array}$ \\
\hline $\begin{array}{l}\text { Coastal Infrastructures } \\
\text { Protection (COASTAL) }\end{array}$ & $\begin{array}{l}\text { Dummy variable. It takes value } 1 \text { if the policy is } \\
\text { chosen and zero otherwise }\end{array}$ \\
\hline $\begin{array}{l}\text { Cultural Heritage Protection } \\
\text { (CULTURE) }\end{array}$ & $\begin{array}{l}\text { Dummy variable. It takes value } 1 \text { if the policy is } \\
\text { chosen and zero otherwise }\end{array}$ \\
\hline AGE & $\begin{array}{l}\text { Takes the value of } 1 \text { for individuals with age } \\
\text { between } 30 \text { and } 60 \text { years, and zero otherwise. }\end{array}$ \\
\hline EDUCATION & $\begin{array}{l}\text { Takes the value of } 1 \text { for individuals with bachelor } \\
\text { degree or higher, zero otherwise. }\end{array}$ \\
\hline INCOME & $\begin{array}{l}\text { Takes the value of } 1 \text { for individuals with monthly } \\
\text { net income higher than } 2.800 € \text {, zero otherwise. }\end{array}$ \\
\hline
\end{tabular}

economic values and tourists' preferences regarding climate change adaptation policies at island destinations. Focus groups were conducted in the different islands under study with a small group of tourists (around ten individuals) prior to the surveying phase. They were organized with the aim to ensure that the questionnaire was going to be clearly understood by the respondents during the fieldwork, and for checking its effectiveness according to the research needs.

The questionnaire was structured in three sections. The first section aimed to identify tourists that were visiting the islands for the first time, and also the duration of the stay. The second and main section was composed by the choice cards. The third and final section asked about the demographic characteristics/profile of tourists (gender, age, education, employment, net monthly income and country of residence).

The questionnaires were implemented in face to face format and were anonymous as no personal information was collected. During the fieldwork, subjects were presented with a definition of each of the impacts that the visited island may be exposed, and the policies to be implemented to counteract these effects. These adaptation policies were described with the aid of words and images After being introduced about the survey and the context of the study, respondents were posed with the choice cards.

In order to make the choice tasks manageable by the respondents, and following results from the focus groups and pre-testing, the number of choice questions was set to 5 . Each choice question card presents two combinations of 9 policy alternatives, plus the no-policy option - or status quo scenario. Thus, the number of $4 \cdot 2^{9}$ potential options were scaled down utilizing an optimal Bayesian design, which has led to a set of 20 pairs of policy alternatives. To do so, the statistical program Ngene was used. Thus, each questionnaire contained 5 choice cards. In total, four different types of questionnaires were prepared and distributed equally within the group of subjects in each island. This way each individual had to answer to five successive cards, and choose only one scenario on each card, considering they were the only options available. In each option there was a price, or the alternative of "Neither Option" (at price $0 €$ ). The price represented an extra price per day tourists would have to pay to reward the adaptation efforts of the destination. Fig. 1 presents an example of one choice card utilized in the choice questions. The supplementary material presents one of the surveys utilized in the fieldwork.

The samples were taken randomly from the tourist population in the respective islands the summer season of 2019. A total of 1853 tourists were interviewed simultaneously at seven different islands destinations: Azores and Madeira (Portugal), Balearic and Canary Islands (Spain), Crete, Sardinia and Sicily (Italy). Tourists were screened to be adults (18 years old or more), should had stayed at least one night at the island, and should have completed at least half of their stay. The field work took place at both weekdays and weekends to capture all groups of tourists. The fieldwork duration was three months.

\section{Results}

\subsection{Value function estimations}

The estimations of the Mixed Logit models for all island destinations are presented in Table 3. The models incorporate the parameterization of the alternative specific constants based on some socioeconomic characteristics of the tourists for each of the island destinations together with the variables defined by the climate change adaptation policy attributes of the choice sets presented to the respondents (Table 2). Thus, the policy attributes do not vary across individuals while the socioeconomic characteristics are specific for each individual tourist, and allows for modelling the heterogeneity in the preferences for the alternative climate change adaptation policy across the sample of tourists.

Mixed Logit allows for the consideration of sample heterogeneity by modelling the climate change policy parameters as dependent on a random term, which in this case has been assumed to follow a normal 


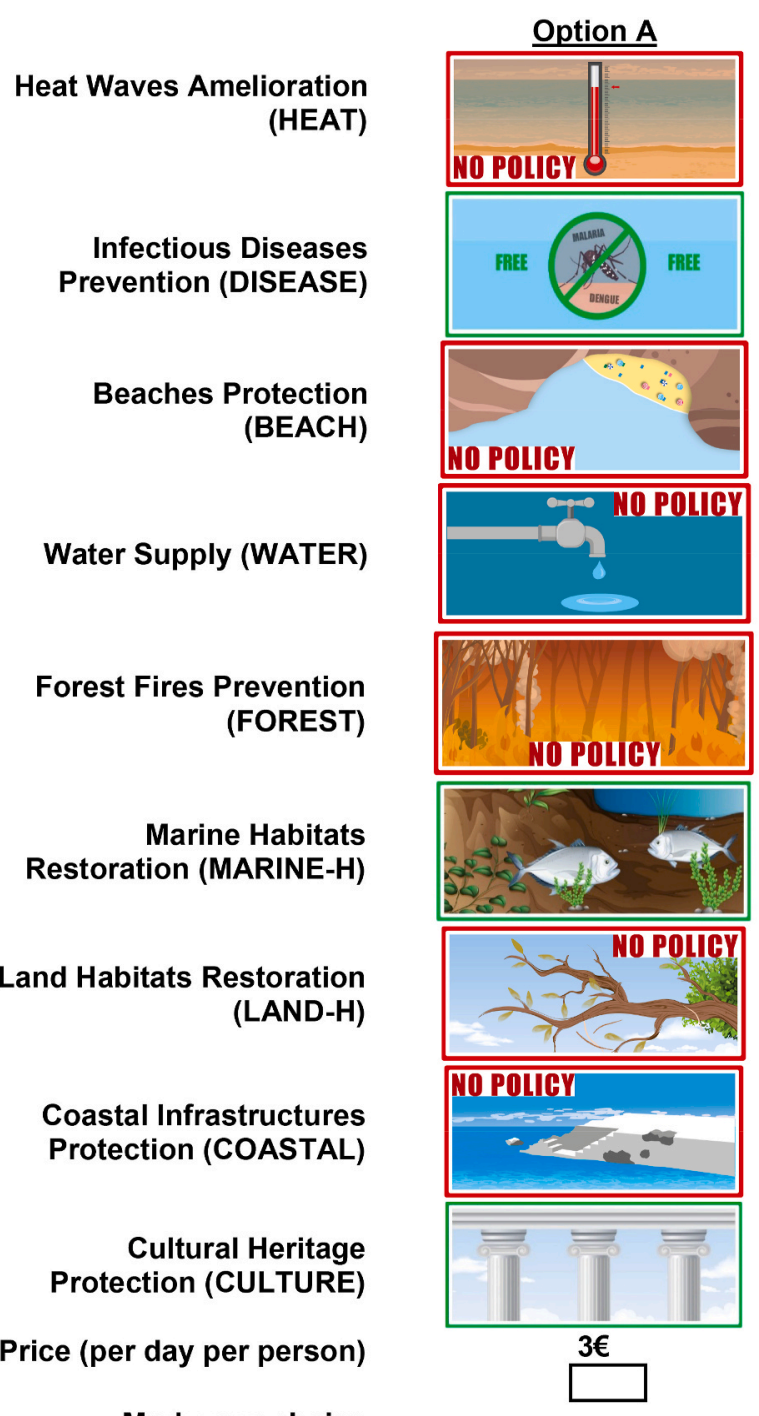

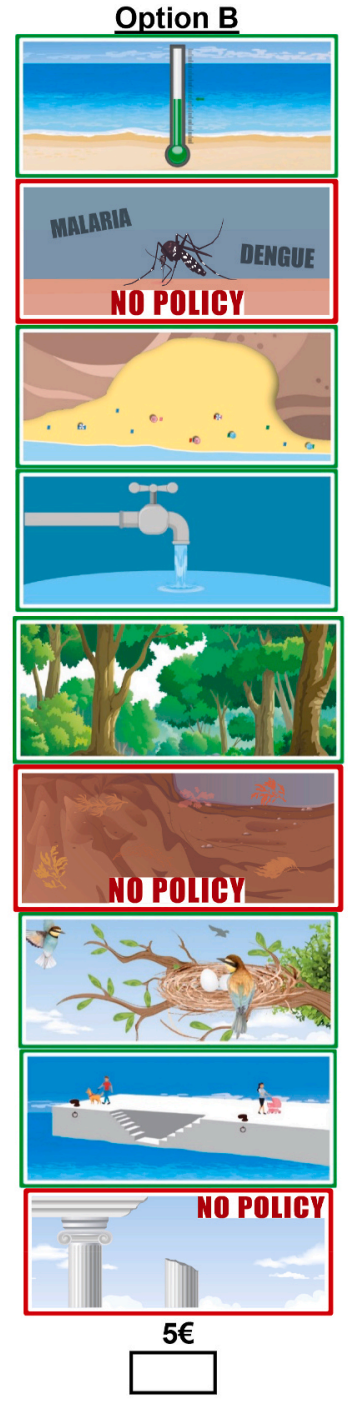

\section{Neither Option}

Mark your choice

Fig. 1. Example of choice card of policy alternatives.

distribution. Therefore, preference parameters vary across individuals reflecting the heterogeneity of tourists' preferences for the policy proposals against climate change impacts in island destinations.

It can be seen that the parameters are highly significant at the 0.01 level for all policy proposals and have a positive sign, indicating that they contribute positively to tourists' utility, and therefore are demanded from the point of view of tourists. That is, the climate change adaptation policies are found to raise tourists' utility and satisfaction, thereby being willing to pay a positive amount of money for their implementation. The price attribute is significant at the 0.01 level for the models of all island destinations, and takes a negative sign, indicating that the higher the price the lower the probability of choosing a policy alternative to counteract climate change impacts.

Thus, tourists show strong positive preferences for the climate change policies at the destinations that should be designed with the aim of fighting the effects of climate change on the natural assets, and coastal and cultural infrastructures of the destinations. These positive preferences are also heterogeneous across the individual respondents as can be seen by the high significance levels of the standard deviations of the preference parameters in the models of all the island destinations.

The policies that raise higher levels of utility across the pool of destinations are the improvement in water supply and the restoration of maritime habitats, followed by the prevention of infectious diseases and the water supply provision. In addition, there are quite similar values across destinations of the parameters contributing to individual utility for the policies of heat wave amelioration and coastal infrastructure protection. The socioeconomic variables of age, income, and education have also some positive and significant effects at some destinations on tourists' choice and preference for a policy option for climate change amelioration.

\subsection{WTP estimations for study and policy sites}

In order to assess the potential transferability of values of the climate change policies across destinations, a valuation function approach is utilized that is based on the pool of available destinations but excluding the one for which transferability is being considered. That is, the data set excluding the predicted destination is utilized as the study sites' available information to estimate a predictive model for each destination. The comparison of the results of this predictive model with those obtained with the actual data of the destination allows for the comparison between the predicted values from the pool of study sites and the observed value of the policy site destination. The utilization of a set of study sites when available in what is called the multi-country or pooled approach to benefit transfer has been proven to be more accurate and leads to lower transfer errors than the benefit transfer based on a single 
Table 3

Mixed Logit estimation results by destination.

\begin{tabular}{|c|c|c|c|c|c|c|c|c|}
\hline Policy & Azores & Balearic & Canaries & Crete & Madeira & Sardinia & Sicily & Pooled \\
\hline \multirow[t]{2}{*}{ Constant } & $3.499 * *$ & -2.378 & $-5.490^{* * *}$ & 1.827 & 0.189 & $5.648^{* * *}$ & -0.723 & $1.059 * *$ \\
\hline & (1.589) & (1.639) & (1.099) & (1.797) & $(1.255)$ & $(1.803)$ & $(0.950)$ & $(0.418)$ \\
\hline \multirow[t]{2}{*}{ PRICE } & $-0.250^{* * *}$ & $-0.253^{* * *}$ & $-0.134 * * *$ & $-0.174 * * *$ & $-0.154^{* * *}$ & $-0.197^{* * *}$ & $-0.254 * * *$ & $-0.205^{* * *}$ \\
\hline & $(0.033)$ & $(0.091)$ & $(0.017)$ & $(0.024)$ & $(0.021)$ & $(0.027)$ & $(0.026)$ & $(0.009)$ \\
\hline \multirow[t]{2}{*}{ HEAT } & $0.623^{* * *}$ & $0,623^{* * *}$ & $0.408^{* * *}$ & $0.669 * * *$ & $0.316^{* * *}$ & $0.407 * * *$ & $0.701^{* * *}$ & $0.546^{* * *}$ \\
\hline & $(0.155)$ & $(0.204)$ & $(0.091)$ & $(0.155)$ & $(0.105)$ & $(0.130)$ & $(0.116)$ & $(0.045)$ \\
\hline \multirow[t]{2}{*}{ DISEASE } & $1.073^{* * *}$ & $1.187^{* * *}$ & $0.998 * * *$ & $1.088^{* * *}$ & $0.652^{* * *}$ & $1.407^{* * *}$ & $1.039^{* * *}$ & $1.117^{* * *}$ \\
\hline & $(0.260)$ & $(0.310)$ & $(0.156)$ & $(0.249)$ & $(0.170)$ & $(0.230)$ & $(0.173)$ & $(0.075)$ \\
\hline \multirow[t]{2}{*}{ BEACH } & $0.598 * * *$ & $0.631 * * *$ & $0.401^{* * *}$ & $1.662 * * *$ & $0.439 * * *$ & $1.582^{* * *}$ & $0.806^{* * *}$ & $0.922^{* * *}$ \\
\hline & $(0.152)$ & $(0.242)$ & $(0.106)$ & $(0.194)$ & $(0.117)$ & $(0.174)$ & $(0.124)$ & $(0.054)$ \\
\hline \multirow[t]{2}{*}{ WATER } & $1.011^{* * *}$ & $0.785^{* * *}$ & $1.415^{* * *}$ & $1.117^{* * *}$ & $1.223^{* * *}$ & $0.822^{* * *}$ & $1.133^{* * *}$ & $1.192^{* * *}$ \\
\hline & $(0.306)$ & $(0.242)$ & $(0.216)$ & $(0.271)$ & $(0.235)$ & $(0.139)$ & $(0.165)$ & $(0.090)$ \\
\hline \multirow[t]{2}{*}{ FOREST } & $0.850 * * *$ & $0.873^{* * *}$ & $0.691 * * *$ & $0.606^{* * *}$ & $0.861^{* * *}$ & $0.424 * * *$ & $0.831^{* * *}$ & $0.776^{* * *}$ \\
\hline & $(0.311)$ & $(0.276)$ & $(0.165)$ & $(0.243)$ & $(0.192)$ & $(0.066)$ & $(0.189)$ & $(0.081)$ \\
\hline \multirow[t]{2}{*}{ MARINE-H } & $2.683^{* * *}$ & $1.030 * * *$ & $1.695^{* * *}$ & $0.793 * * *$ & $1.620 * * *$ & $1.501^{* * *}$ & $1.529 * * *$ & $1.645^{* * *}$ \\
\hline & $(0.265)$ & $(0.318)$ & $(0.155)$ & $(0.228)$ & $(0.177)$ & $(0.219)$ & $(0.202)$ & $(0.073)$ \\
\hline \multirow[t]{2}{*}{ LAND-H } & $1.498 * * *$ & $0.646 * * *$ & $0.842^{* * *}$ & $0.376^{* * *}$ & $0.644 * * *$ & $0.775^{* * *}$ & $0.879^{* * *}$ & $0.836^{* * *}$ \\
\hline & $(0.295)$ & $(0.219)$ & $(0.190)$ & $(0.268)$ & $(0.210)$ & $(0.259)$ & $(0.231)$ & $(0.087)$ \\
\hline \multirow[t]{2}{*}{ COASTAL } & $0.593^{* * *}$ & $0.785^{* * *}$ & $0.811^{* * *}$ & $0.628^{* * * *}$ & $0.522^{* * *}$ & $0.674 * * *$ & $0.605^{* * *}$ & $0.712^{* * *}$ \\
\hline & $(0.129)$ & $(0.309)$ & $(0.147)$ & $(0.198)$ & $(0.165)$ & $(0.204)$ & $(0.163)$ & $(0.066)$ \\
\hline \multirow[t]{2}{*}{ CULTURAL } & $0.965^{* * *}$ & $0.638^{* * *}$ & $0.867 * * *$ & $0.270 * * *$ & $0.541^{* * *}$ & $0.524 * * *$ & $0.729 * * *$ & $0.687^{* * *}$ \\
\hline & $(0.291)$ & $(0.220)$ & $(0.176)$ & $(0.112)$ & $(0.196)$ & $(0.173)$ & $(0.296)$ & $(0.083)$ \\
\hline \multirow[t]{2}{*}{ AGE } & $0.116^{* * *}$ & $0.040 * * *$ & $0.016^{* * *}$ & 0.011 & $0.045^{* * *}$ & 0.012 & 0.007 & $0.045^{* * *}$ \\
\hline & $(0.021)$ & $(0.010)$ & $(0.006)$ & $(0.012)$ & $(0.007)$ & $(0.013)$ & $(0.007)$ & $(0.013)$ \\
\hline \multirow[t]{2}{*}{ EDUCATION } & 0.608 & $2.059 * *$ & $0.419 *$ & $2.070 * * *$ & 0.206 & $1.423^{* *}$ & $0.251^{* *}$ & $0.959^{* * *}$ \\
\hline & $(0.421)$ & $(0.937)$ & $(0.245)$ & $(0.743)$ & $(0.277)$ & $(0.719)$ & $(0.125)$ & $(0.118)$ \\
\hline \multirow[t]{2}{*}{ INCOME } & 0.495 & $0.475^{* *}$ & $0.295^{*}$ & 0.085 & $0.320 *$ & $1.128 * * *$ & 0.343 & $0.376^{* * *}$ \\
\hline & $(0.352)$ & $(0.240)$ & $(0.175)$ & $(0.378)$ & $(0.191)$ & $(0.360)$ & $(0.296)$ & $(0.082)$ \\
\hline \multicolumn{9}{|c|}{ Standard deviation of random parameters } \\
\hline \multirow[t]{2}{*}{ HEAT } & $0.920^{* * *}$ & $0.960 * * *$ & 0.243 & $1.070^{* * *}$ & $0.514^{* * *}$ & $-0.728^{* * *}$ & $0.801^{* * *}$ & $0.733^{* * *}$ \\
\hline & $(0.196)$ & $(0.198)$ & $(0.194)$ & $(0.154)$ & $(0.142)$ & $(0.167)$ & $(0.126)$ & $(0.055)$ \\
\hline \multirow[t]{2}{*}{ DISEASE } & $1.183^{* * *}$ & $-0.596^{* *}$ & $0.670 * * *$ & $1.864 * * *$ & $0.598^{* * *}$ & $1.228^{* * *}$ & $0.454^{* * *}$ & $0.911^{* * *}$ \\
\hline & $(0.204)$ & $(0.300)$ & $(0.129)$ & $(0.192)$ & $(0.151)$ & $(0.175)$ & (0.169) & $(0.056)$ \\
\hline \multirow[t]{2}{*}{ BEACH } & $0.850 * * *$ & $0.654 * *$ & -0.252 & $1.413^{* * *}$ & -0.230 & $1.182^{* * *}$ & $0.587^{* * *}$ & $0.851^{* * *}$ \\
\hline & (0.199) & $(0.278)$ & $(0.182)$ & $(0.161)$ & $(0.205)$ & $(0.178)$ & $(0.149)$ & $(0.054)$ \\
\hline \multirow[t]{2}{*}{ WATER } & $0.959 * *$ & 0.496 & $1.248 * * *$ & $1.563^{* * * *}$ & $1.351^{* * *}$ & $1.342^{* * *}$ & $0.716^{* * *}$ & $1.258^{* * *}$ \\
\hline & $(0.477)$ & $(0.774)$ & $(0.230)$ & $(0.304)$ & $(0.256)$ & $(0.281)$ & $(0.217)$ & $(0.095)$ \\
\hline$N$ & 2292 & 2754 & 3618 & 4104 & 2931 & 2943 & 3456 & 22098 \\
\hline R2_p & 0.35 & 0.41 & 0.29 & 0.30 & 0.18 & 0.23 & 0.28 & 0.31 \\
\hline Log-likelihood & -594.500 & -545.276 & -1160.262 & -997.203 & -940.443 & -740.858 & -949.619 & -6703.821 \\
\hline Chi-2 & 50.348 & 18.943 & 38.665 & 220.110 & 36.545 & 95.235 & 30.994 & 447.431 \\
\hline
\end{tabular}

Standard errors in parentheses.

${ }^{*} p<0.1 ;{ }^{* *} p<0.05 ;{ }^{* *} p<0.01$.

study (Brouwer et al., 2015; Colombo \& Hanley, 2008; Johnston et al., 2021). Based on this and due to the number of sites in this study, we do not present results from the single study site transfer approach in this paper.

Table 4 shows the results of the WTP value estimates from the Mixed Logit model for the predictive and the policy site models for each destination. For the predictive models, the results of the estimation of the predictive WTP for each island destination is based on the mean values of the corresponding socioeconomic variables of tourists. The policies which are most valued by tourists across all destinations are the policies designed to deal with marine habitats protection, water supply guarantee and infectious disease prevention. For the policy of marine habitats protection, the average value across all destinations stands out at $8.02 €$ per individual tourist, ranging from the lowest value of $4.7 €$ for the Balearics to the highest value of $12.65 €$ for the Canaries. For the policy of guaranteeing adequate water supply at the island destinations during the tourist visits, the average value is $5.81 €$ across destinations, varying between $3.10 €$ for Balearics and $10.56 €$ for the Canaries. And for the policy of preventing infectious diseases at the destinations, the average value across all destinations is $5.45 €$, oscillating between $4.09 €$ for Sicily and $7.45 €$ for the Canaries.

Looking at the overlapping of the confidence intervals between the predicted study sites model and the policy site for each of the island destinations provides a first approximation to the potential transferability of the predicted values for the island destinations. The results in Table 4 show significant overlapping of the confidence intervals of mean WTP values across policies for 44 policy values out of a total of 63 policy values. The destination with more policies for which there are more overlapping in confidence intervals is Sicily with all values showing considerable overlapping in confidence intervals, followed by Sardinia and Balearics, for which there are eight out of nine policies with significant overlapping. The Canary Islands shows the lowest number of policies with significant overlapping -only three, while Madeira and Crete have six policies with large overlapping. Based on the criteria of the overlapping intervals, it can be shown that the policy for which there is potentially more valid transfers across islands is the heat wave amelioration, since for this there are relevant overlapping in all islands under study. The policies for which the overlapping of confidence intervals is less successful to ensure transferability are the marine habitats restoration and water supply policies, for which there are more disparities of economic values across islands, with only three out of seven islands showing relevant overlapping in confidence intervals.

\subsection{Tests of benefit transfer}

The main research question of this paper is to what extent the valuation of climate change adaptation policies can be transferred between island destinations, based on the availability of a pool of study sites that provides information that can be utilized to extrapolate results to the policy sites. To fully answer this question, it should be considered 
Table 4

Tourists' WTP for adaptation policies in the predictive and observed policy sites models (in $€$ ) (confidence intervals in brackets).

\begin{tabular}{|c|c|c|c|c|c|c|}
\hline \multirow[t]{2}{*}{ Policy } & \multicolumn{2}{|l|}{ Azores } & \multicolumn{2}{|l|}{ Balearic } & \multicolumn{2}{|l|}{ Canaries } \\
\hline & Obs. & Pred. & Obs. & Pred. & Obs. & Pred. \\
\hline \multirow[t]{2}{*}{ HEAT } & 2.49 & $2.98^{\mathrm{a}}$ & 2.37 & $2.72^{\mathrm{a}}$ & 3.04 & $2.43^{\mathrm{a}}$ \\
\hline & {$[2.04 ; 3.62]$} & {$[2.59 ; 3.36]$} & {$[1.96 ; 3.08]$} & {$[1.92 ; 3.20]$} & {$[1.96 ; 3.93]$} & {$[2.10 ; 2.76]$} \\
\hline \multirow[t]{2}{*}{ DISEASE } & 4.29 & $4.09^{\mathrm{a}}$ & 4.69 & $4.31^{\mathrm{a}}$ & 7.45 & 3.78 \\
\hline & {$[3.36 ; 5.23]$} & {$[3.70 ; 4.48]$} & {$[4.10 ; 5.18]$} & {$[3.92 ; 4.93]$} & {$[4.99 ; 9.90]$} & {$[3.44 ; 4.12]$} \\
\hline \multirow[t]{2}{*}{ BEACH } & 2.39 & $3.43^{\mathrm{a}}$ & 2.49 & $3.03^{\mathrm{a}}$ & 2.99 & $3.28^{\mathrm{a}}$ \\
\hline & {$[1.56 ; 3.73]$} & {$[3.06 ; 3.81]$} & {$[1.61 ; 3.11]$} & {$[1.82 ; 3.43]$} & {$[1.30 ; 4.68]$} & {$[2.95 ; 3.62]$} \\
\hline \multirow[t]{2}{*}{ WATER } & 4.04 & 4.11 & 3.10 & $3.41^{\mathrm{a}}$ & 10.56 & 3.83 \\
\hline & {$[3.05 ; 4.82]$} & {$[3.52 ; 4.70]$} & {$[2.51 ; 3.43]$} & {$[2.61 ; 3.86]$} & {$[6.62 ; 14.49]$} & {$[3.31 ; 4.36]$} \\
\hline \multirow[t]{2}{*}{ FOREST } & 3.4 & $3.11^{\mathrm{a}}$ & 3.45 & $3.2^{\mathrm{a}}$ & 5.16 & $3.01^{\mathrm{a}}$ \\
\hline & {$[2.01 ; 4.80]$} & {$[2.53 ; 3.69]$} & {$[2.91 ; 3.86]$} & {$[2.88 ; 3.81]$} & [2.33;7.99] & {$[2.49 ; 3.53]$} \\
\hline \multirow[t]{2}{*}{ MARINE-H } & 10.73 & 4.66 & 4.07 & 6.35 & 12.65 & 5.06 \\
\hline & {$[8.54 ; 12.93]$} & {$[4.06 ; 5.27]$} & {$[3.30 ; 4.37]$} & {$[5.05 ; 6.03]$} & {$[8.15 ; 17.14]$} & {$[4.51 ; 5.61]$} \\
\hline \multirow[t]{2}{*}{ LAND-H } & 5.99 & 3.02 & 2.55 & $2.98^{\mathrm{a}}$ & 6.28 & 3.29 \\
\hline & {$[4.45 ; 7.54]$} & {$[2.42 ; 3.62]$} & {$[2.08 ; 3.27]$} & {$[2.21 ; 3.33]$} & {$[3.23 ; 9.33]$} & {$[2.75 ; 3.82]$} \\
\hline \multirow[t]{2}{*}{ COASTAL } & 2.37 & $2.48^{\mathrm{a}}$ & 3.10 & $2.48^{\mathrm{a}}$ & 6.05 & 2.08 \\
\hline & {$[1.15 ; 3.59]$} & {$[1.93 ; 3.03]$} & {$[2.74 ; 3.60]$} & {$[2.22 ; 3.68]$} & {$[3.13 ; 8.97]$} & [1.59; 2.56] \\
\hline \multirow[t]{2}{*}{ CULTURE } & 3.86 & 2.43 & 2.52 & $2.81^{\mathrm{a}}$ & 6.47 & 2.28 \\
\hline & {$[2.58 ; 5.13]$} & {$[1.87 ; 2.99]$} & {$[1.93 ; 2.92]$} & {$[2.03 ; 3.12]$} & {$[3.49 ; 9.44]$} & {$[1.78 ; 2.78]$} \\
\hline
\end{tabular}

Obs. = Observed; Pred. = Predicted.

aSignificantly overlapping confidence intervals.

what are the transfer errors that are observed when the set of study sites is utilized for assessing the values of the policy sites and to what extent the differences between the observed and transferred values are statistically significant.

Table 5 presents the transfer errors estimated for all destinations and the implicit prices of the climate change adaptation policies. Average transfer error across all adaptation policies and tourist destinations is 29.2 per cent, which is within the 30 per cent bound acceptable for transferability in empirical research (Brouwer et al., 2015, 2016). There are some destinations with higher transfer errors averaged across adaptation policies, such as the Canaries (46.9), Crete (41.7) Sardinia (31.9) and Madeira (30). Sicily is the destination with lower average transfer error (10.3). Transfer errors differ also on average between climate change adaptation policies, but with less variability than for destinations.

Fig. 2 depicts the cumulative distribution of transfer errors for the 63 policy evaluations in the pool of policy sites or tourist destinations. It can be seen that more than 50 per cent of the policies evaluated show transfer errors below $25 \%$. There are 16 assessments ( 25 per cent of the total) with less than 10 per cent transfer errors, 20 (31 per cent of the total) with a transfer error between 10 and 30 per cent, and 27 (43 per cent of the total) policy evaluations with a transfer error higher than 30 per cent.

Table 6 shows the results of the S-L, Poe and TOST tests for the implicit prices or WTP values of all the climate change policies in island destinations. The statistics $\left(\chi^{2}\right)$ of the S-L test are all higher than the value of $\chi^{2}$ at $5 \%$ level for 19 degrees of freedom (30.10) indicating that the transfer of the valuation function is rejected in all destinations, since some of the parameters of the models for each destination (policy site model) are significantly different than the parameters of the pooled transfer model.

The Poe and TOST tests focus on the transferability of the implicit prices (i.e. WTP values) rather than the full set of structural parameters of the valuation function. Both tests have different interpretations of the p-values. Whereas the null hypothesis in the Poe et al. test is the equality of values of the implicit prices in the TOST test the null is that the implicit prices have a difference that is larger than $20 \%$. Thus, rejecting of the null for the TOST test implies the estimates of the policy site and the study site are closer than $20 \%$.

Some of the islands have a better performance than others in terms of the statistical significance of the equality between the implicit prices obtained with the transfer function (study site) and those observed with the on-site sample (policy site). Based on these results, Sicily stands out as the only island for which all the climate change adaptation policies can be successfully transferred based on the pool of studies of the other islands. For this island, both tests allow for rejection of significant differences in the implicit prices for all policies. In two other islands, the null hypotheses of equality of values is rejected only for one of the climate change adaptation policies, i.e. in the case of Crete for the infectious disease prevention and in the case of Balearics for the marine habitat restoration. For Madeira, only two polices cannot be successfully transferred, i.e. water supply infrastructures and forest fire prevention measures. Thus, four of the islands (Balearics, Crete, Sicily and Madeira) find a high level of transferability based on the large number of climate change policies for which the transfer tests are passed.

There is another group of islands for which the transfer tests produce less successful results. This is the case of the Sardinia, Canaries and the Azores. For the Sardinia and Canaries, test results are failed for six out of the nine climate change adaptation policies, while for Azores the number of failed transfer tests is four. Out of the total of 63 potential transfer values of climate change policies between the study sites and each of the islands, the transfer tests are failed for 20 , i.e. transferability of values is rejected in 31 per cent of the policies considered. This suggests that transferability of climate change policies across island tourist destinations is more feasible for those islands within the Mediterranean basin rather than for those islands that are geographically placed in more remote places over the Atlantic sea.

Considering the potential transferability of the specific values of climate change policies across islands, there are some policies that can be more widely transferred than others. For instance, for the policy of heat wave amelioration, transferability is passed for all island destinations considered, since both tests do not reject the hypothesis of equality of values between the policy site and the pool of study sites. Similarly, the policies of beach protection measures only fail transferability in the case of Sardinia, successfully passing the equality of values between policy and study sites for all other destinations. Similarly, there are only two islands for which transferability is rejected for the policies of infectious disease prevention (Sardinia and Crete) and land habitat restoration (Azores and Canaries). The policy of forest fire prevention, water supply infrastructure, and coastal infrastructure protection failed transferability for three of the islands considered. Finally, the policy of marine habitat restoration had the least successfully transferred value 


\begin{tabular}{|c|c|c|c|c|c|c|c|}
\hline \multicolumn{2}{|l|}{ Crete } & \multicolumn{2}{|l|}{ Madeira } & \multicolumn{2}{|l|}{ Sardinia } & \multicolumn{2}{|l|}{ Sicily } \\
\hline Obs. & Pred. & Obs. & Pred. & Obs. & Pred. & Obs. & Pred. \\
\hline 3.84 & $3.50^{\mathrm{a}}$ & 2.05 & $2.68^{\mathrm{a}}$ & 2.06 & $2.5^{\mathrm{a}}$ & 2.76 & $2.58^{\mathrm{a}}$ \\
\hline$[2.39 ; 4.98]$ & {$[2.73 ; 4.39]$} & {$[0.64 ; 3.45]$} & {$[2.33 ; 3.03]$} & {$[1.52 ; 3.74]$} & {$[2.16 ; 2.85]$} & {$[2.20 ; 3.32]$} & {$[2.17 ; 3.00]$} \\
\hline 6.25 & 3.85 & 4.23 & $4.02^{\mathrm{a}}$ & 7.14 & 3.84 & 4.09 & $4.33^{\mathrm{a}}$ \\
\hline$[4.42 ; 8.08]$ & {$[3.50 ; 4.20]$} & {$[4.28 ; 4.61]$} & {$[3.66 ; 4.38]$} & {$[5.21 ; 9.06]$} & {$[3.48 ; 4.19]$} & {$[3.54 ; 4.98]$} & {$[3.89 ; 4.76]$} \\
\hline 9.55 & 2.54 & 2.85 & $3.31^{\mathrm{a}}$ & 8.03 & 2.81 & 3.17 & $3.54^{\mathrm{a}}$ \\
\hline$[6.96 ; 12.15]$ & {$[2.21 ; 2.87]$} & {$[1.41 ; 4.29]$} & {$[2.96 ; 3.66]$} & {$[5.80 ; 10.27]$} & {$[2.47 ; 3.16]$} & {$[3.01 ; 3.86]$} & {$[3.12 ; 3.97]$} \\
\hline 6.42 & 4.29 & 7.94 & 4.14 & 4.17 & $4.58^{\mathrm{a}}$ & 4.46 & $5.17^{\mathrm{a}}$ \\
\hline$[3.91 ; 8.92]$ & {$[3.74 ; 4.85]$} & {$[5.01 ; 10.8]$} & {$[3.58 ; 4.69]$} & {$[3.87 ; 5.36]$} & {$[4.01 ; 5.15]$} & {$[3.96 ; 5.20]$} & {$[4.47 ; 5.87]$} \\
\hline 3.48 & $3.12^{\mathrm{a}}$ & 5.59 & 2.98 & 2.15 & 3.27 & 3.27 & $3.11^{\mathrm{a}}$ \\
\hline$[1.27 ; 5.69]$ & {$[2.58 ; 3.65]$} & {$[3.05 ; 8.13]$} & {$[2.44 ; 3.52]$} & {$[2.30 ; 4.29]$} & {$[2.73 ; 3.82]$} & {$[2.47 ; 4.06]$} & {$[2.45 ; 3.76]$} \\
\hline 4.56 & $5.82^{\mathrm{a}}$ & 10.52 & 5.29 & 7.62 & $5.67^{\mathrm{a}}$ & 6.02 & $6.42^{\mathrm{a}}$ \\
\hline$[2.25 ; 6.86]$ & {$[5.23 ; 6.41]$} & {$[7.10 ; 13.93]$} & {$[4.71 ; 5.87]$} & {$[5.16 ; 10.09]$} & {$[5.07 ; 6.27]$} & {$[5.29 ; 7.02]$} & {$[5.70 ; 7.13]$} \\
\hline 2.16 & $3.66^{\mathrm{a}}$ & 4.18 & $3.48^{\mathrm{a}}$ & 3.93 & $2.9^{\mathrm{a}}$ & 3.46 & $3.96^{\mathrm{a}}$ \\
\hline$[-0.15 ; 4.47]$ & {$[3.11 ; 4.22]$} & {$[1.82 ; 6.54]$} & {$[2.92 ; 4.04]$} & {$[2.02 ; 4.84]$} & {$[2.34 ; 3.74]$} & {$[3.16 ; 4.40]$} & {$[3.31 ; 4.61]$} \\
\hline 3.61 & $2.35^{\mathrm{a}}$ & 3.39 & $2.36^{\mathrm{a}}$ & 3.42 & $2.36^{\mathrm{a}}$ & 2.38 & $2.61^{\mathrm{a}}$ \\
\hline$[1.40 ; 5.81]$ & {$[1.85 ; 2.84]$} & {$[1.14 ; 5.64]$} & {$[1.85 ; 2.86]$} & {$[1.37 ; 5.48]$} & {$[1.85 ; 2.88]$} & {$[1.88 ; 3.52]$} & {$[2.01 ; 3.22]$} \\
\hline 1.55 & $2.77^{\mathrm{a}}$ & 3.51 & $2.58^{\mathrm{a}}$ & 2.66 & $2.93^{\mathrm{a}}$ & 2.87 & $2.37^{\mathrm{a}}$ \\
\hline$[-0.67 ; 3.77]$ & {$[2.26 ; 3.28]$} & {$[1.24 ; 5.78]$} & {$[2.06 ; 3.10]$} & {$[2.09 ; 3.83]$} & {$[2.41 ; 3.46]$} & {$[1.74 ; 3.44]$} & {$[1.75 ; 2.98]$} \\
\hline
\end{tabular}

since it fails transferability tests in four (Azores, Balearics, Canaries and Sardinia) out of seven island destinations considered.

\section{Discussion}

Island destinations are going to have important impacts from climate change, affecting the environmental attributes that traditionally have been utilized for the production of tourist services (Susanto et al., 2020). Therefore, there is need to undertake adaptation policies that ameliorate the physical and economic damages caused by climate change in island destinations. The measurement of the economic values of these policies through available economic valuation techniques is costly and there is need to find other more efficient ways of appraising the benefits of climate change policies (Cashman et al., 2012; Atzori et al., 2018). Benefit transfer offers an efficient alternative for the economic appraisal of the benefits generated by environmental and climate change policies, but has not been yet employed in a tourism context.

The economic values obtained for climate change adaptation policies in tourism destinations add to the available information that is useful for undertaking further benefit transfer and meta-analysis studies. Although no study so far has tackled simultaneously the economic values of the set of climate change policies of the present paper, there are available studies investigating some of these policies. For instance, Nunes et al. (2015) found that the per tourist visit average WTP for lowering the risk of jelly fish blooms in Catalonian coasts was $3.20 €$. However, utilizing CVM, Schuhmann et al. (2019) found a much higher WTP (between 36 and 52 US\$ per tourist visit) for coastal and marine ecosystems conservation in Barbados. Also utilizing CVM, Koutrakis et al. (2011) found that visitors' WTP for beach defences in coastal Mediterranean areas of Greece, France and Italy was between $€ 0.5-1.49$ per day.

Focusing on the adaptation plans for the climate change impacts on bird species in wetlands in Majorca (Spain), DCE results by Faccioli et al. (2015) found that tourists WTP was $1 €$ per visit for migratory bird species and $1.31 €$ per visit for specialist bird species. Also in Mallorca, the DCE reported in Enríquez and Bestard (2020) evaluated the economic impacts of some climate damages on tourists' welfare, finding a higher economic value per visitor for the impact of beach retreat $(1.23 €$ per meter) than for the closure of beaches due to jelly fish outbreaks ( $0.9 €$ per day of closure) and the reduction of a $1 \%$ of seagrass ecosystems of Posidonia oceanica ( $0.31 €$ per day of stay).

Regarding the potential impacts of forest fires, Bonnieux et al. (2006) investigated preferences for forest management in the Corsican forest (Mediterranean) utilizing DCE, finding that visitors were willing to pay $5 €$ for fire protection and $3.2 €$ for the preservation of flora and fauna (land ecosystems). These are very similar values to the ones obtained in the present study for the elicited WTP of tourists visiting the seven islands destinations. However, the results of the present paper as well as those obtained in Bonnieux et al. (2006) may be influenced by the events of extreme heats and fires that have occurred during the summer in which the research were conducted.

The results of the benefit transfer tests for climate change adaptation policies in tourism destinations in this paper are in line with other studies of benefit transfer in other contexts. Because of space limitations, in this paper we have utilized a multi-country approach to benefit transfer as opposed to the single country approach. The latter involves comparing the results of benefit transfer between pair of policy sites (or destinations), while the former consists of pooling the data from a set of countries to build up the study site prediction for the policy site. Colombo and Hanley (2008) and Brouwer et al. (2015) found that the multi-country approach led to lower transfer errors than the single country approach. Although not reported here, the results for the climate change policies are in line with these findings. That is, multi-country or multi-destination benefit transfer is more appropriate if information is available on a set of destinations, since the larger the amount of information the more accurate is the prediction for the policy site destination.

Further, the present paper also focuses on the valuation function transfer modelling of DCE data with the consideration of socioeconomic characteristics, which has been proven to be a modelling strategy that reduces transfer errors in comparison with other data modelling alternatives (Colombo et al., 2007). That is, the results in the literature are consistent in that the transfer errors are reduced with a valuation function transfer instead of a single value transfer approach is adopted, and when controlling for unobserved preference heterogeneity in discrete choice modelling by utilizing a random parameter or mixed logit model as in the present paper (Brouwer et al., 2015). Further, transfer errors are also reduced when socioeconomic characteristics are incorporated into the value function model to account for observed preference heterogeneity (Brouwer et al., 2015; Colombo et al., 2007).

The transfer errors obtained in this research are also in line with the benchmarks encountered in the available literature, suggesting that the benefit transfer method offers a promising efficient alternative to the 
Table 5

Transfer errors.

\begin{tabular}{|c|c|c|c|c|c|c|c|c|}
\hline Policy & Azores & Balearics & Canaries & Crete & Madeira & Sardinia & Sicily & Average \\
\hline HEAT & 19.7 & 14.7 & 20.2 & 8.9 & 30.7 & 21.1 & 6.5 & 17.4 \\
\hline DISEASE & 4.7 & 8.1 & 49.3 & 38.4 & 5.0 & 46.2 & 5.8 & 22.5 \\
\hline BEACH & 43.5 & 21.5 & 9.7 & 73.4 & 16.1 & 65.0 & 11.6 & 34.4 \\
\hline WATER & 1.6 & 10.0 & 63.7 & 33.2 & 47.9 & 9.8 & 15.9 & 26.0 \\
\hline FOREST & 8.5 & 7.3 & 41.7 & 10.3 & 46.7 & 52.1 & 4.9 & 24.5 \\
\hline MARINE-H & 49.6 & 16.8 & 47.6 & 69.4 & 16.7 & 26.2 & 14.5 & 34.4 \\
\hline LAND-H & 56.6 & 56.0 & 60.0 & 27.6 & 49.7 & 25.6 & 6.6 & 40.3 \\
\hline COASTAL & 4.6 & 20.1 & 65.6 & 34.9 & 30.4 & 31.0 & 9.7 & 28.0 \\
\hline CULTURE & 37.0 & 11.6 & 64.8 & 78.7 & 26.5 & 10.2 & 17.5 & 35.2 \\
\hline Average & 25.1 & 18.5 & 46.9 & 41.7 & 30.0 & 31.9 & 10.3 & 29.2 \\
\hline
\end{tabular}

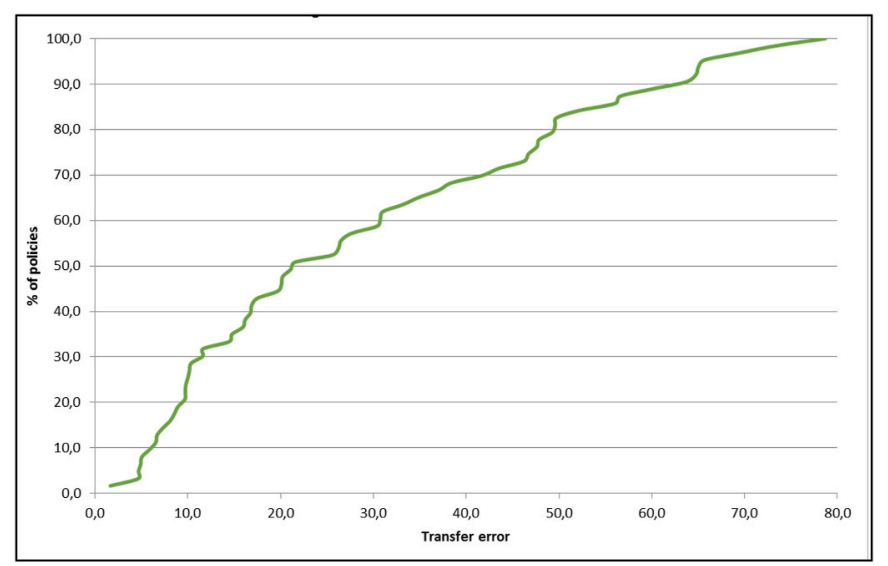

Fig. 2. Transfer errors distribution.

valuation of environmental assets and policies in a tourist context. The review conducted by Rosenberg (2015) of 38 benefit transfer studies showed value function transfer errors can vary in a range from very low (less than 1\%) to very high (high than $900 \%$ ) with a mean of $65 \%$ and a median of $36 \%$. Transfer errors are higher for unit value transfer and when populations or study sites are dissimilar to each other. According to Johnston et al. (2015), the evaluation studies of transfer errors are most similar and intuitive in highlighting the outperformance of function over unit value transfers and the importance policy site similarities (Brouwer \& Spaninks, 1999; Rosenberger \& Stanley, 2006).

\section{Conclusions}

The tourism industry is threatened by potential climate change impacts, since both the supply and the demand of tourist services depend upon the quality and management of environmental attributes that are under threat of modification by the expected changes in temperature and sea level rise (Gössling et al., 2012; Gómez-Martín et al., 2014). The design and promotion of adaptation and prevention policies are becoming increasingly urgent in order to accommodate to the expected changes in the industry, and therefore reduce the socioeconomic costs that the future changes in environmental industry will have on the societies of destinations.

Since the accomplishment of climate change adaptation policies is costly there is need to evaluate the economic benefits that their undertaking would generate. Valuation of social policies is also by itself a costly endeavour in terms of time, skills and human resources. The technique of benefit transfer offers the possibility of utilizing past information on the economic values of tourist policies for the assessment of the policies which are projected in similar contexts and scenarios for which there would be need to undertake a specific valuation task (Johnston et al., 2021; Kemperman, 2021). This approach is widely utilized in other areas of science for which there are vast amounts of empirical evidence about specific problems, and which have also extensive replications available of experiments and studies (Haidich, 2010). However, in tourism studies the utilization of past information on case studies for projecting expected results in new situations is largely an unexplored area of methodological research.

From a scientific perspective, this paper has tested, for the first time in a tourism policy context, the validity of the benefits transfers method of the economic values of the policies to adapt to climate change impacts. In this regard, a pool of seven study sites was utilized to extrapolate results to policy sites. This multi-country approach, join to the utilization of empirical data coming from DCE, and the consideration of tourists' socioeconomic characteristics led to a low transfer error.

From a managerial perspective, the results are useful for the design and valuation of climate change policies at island tourist destinations utilizing a more efficient approach with benefit transfer. Since the climate change policies valued are the same across all destinations, the proposed approach can control for the potential differences in the economic values that come out from the heterogeneity in tourists' preferences and socioeconomic conditions.

The practical contribution of the study is twofold. First, empirical findings may help tourism practitioners and policy-makers of the studied islands to identify adaptation efforts that have the potential to improve tourists' perceived wellbeing and thus develop destinations' plans accordingly. Secondly, the study opens a new opportunity for destinations to utilise past information for the impact assessment of their

Table 6

S-L, Poe and TOST tests for transferability of climate change policies implicit prices.

\begin{tabular}{|c|c|c|c|c|c|c|c|c|c|c|c|c|c|c|}
\hline Island & Azores & & Balearics & & Canaries & & Crete & & Madeira & & Sardinia & & Sicily & \\
\hline Swait-Louviere tests $\left(\chi^{2}\right)$ & 50.41 & & 36.37 & & 61.53 & & 55.21 & & 48.30 & & 40.28 & & 51.24 & \\
\hline Policy (p-values) & Poe & TOST & Poe & TOST & Poe & TOST & Poe & TOST & Poe & TOST & Poe & TOST & Poe & TOST \\
\hline HEAT & 0.4644 & 0.0679 & 0.2283 & 0.0472 & 0.3086 & 0.0704 & 0.1979 & 0.0792 & 0.3351 & 0.0407 & 0.3274 & 0.0311 & 0.4419 & 0.0165 \\
\hline DISEASE & 0.5489 & 0.0662 & 0.2877 & 0.0806 & 0.7090 & 0.0262 & 0.0234 & 0.5840 & 0.1527 & 0.0901 & 0.0593 & 0.5622 & 0.3580 & 0.0582 \\
\hline BEACH & 0.3207 & 0.0735 & 0.4772 & 0.0153 & 0.3884 & 0.0699 & 0.5984 & 0.0403 & 0.1390 & 0.0614 & 0.0215 & 0.6501 & 0.4040 & 0.0416 \\
\hline WATER & 0.6606 & 0.0320 & 0.2408 & 0.0499 & 0.0718 & 0.7873 & 0.6465 & 0.4818 & 0.0396 & 0.6286 & 0.0988 & 0.1575 & 0.2873 & 0.0511 \\
\hline FOREST & 0.7325 & 0.0653 & 0.1584 & 0.0527 & 0.0743 & 0.4967 & 0.1954 & 0.0645 & 0.0558 & 0.5469 & 0.0423 & 0.2009 & 0.6945 & 0.0129 \\
\hline MARINE-H & 0.0834 & 0.5958 & 0.2442 & 0.0685 & 0.0315 & 0.5761 & 0.2574 & 0.0644 & 0.3011 & 0.0675 & 0.2559 & 0.0825 & 0.2263 & 0.0245 \\
\hline LAND-H & 0.0203 & 0.4657 & 0.0910 & 0.4603 & 0.0219 & 0.5580 & 0.1165 & 0.0763 & 0.8887 & 0.0397 & 0.0439 & 0.1859 & 0.6231 & 0.0645 \\
\hline COASTAL & 0.0435 & 0.1664 & 0.3712 & 0.0773 & 0.0287 & 0.7762 & 0.1702 & 0.0469 & 0.4407 & 0.0424 & 0.0769 & 0.2299 & 0.2081 & 0.0387 \\
\hline CULTURE & 0.0477 & 0.4005 & 0.4048 & 0.0461 & 0.0298 & 0.7776 & 0.5704 & 0.0917 & 0.4905 & 0.0395 & 0.2222 & 0.0532 & 0.3418 & 0.0305 \\
\hline
\end{tabular}


climate-related adaptation plans, speeding up the implementation of climate action in more cost efficient terms. This research is even more valuable in the current climate emergency, since the tourism sector and the tourism academy have shown to lack strong capacity to provide the massive information requirements for climate change adaptation (Scott, 2021).

Although the results show that tourists value the climate change policies in all destinations, it is worth noting that the transferability of the values across destinations cannot be accepted for all policies. Full transferability of values based on the valuation function is rejected for all island destinations, but the acceptance of partial transferability of values for some climate change policies gives some support to the application of the benefit transfer method. Transfer errors are within the acceptable bounds for satisfactory results found in other areas of research in non-market valuation with benefit transfer. The transferability of values cannot be rejected in the majority of destinations for the policies concerned with forest fires protection and coastal infrastructure protection. These results give strong support to the utilization of the transfer method across tourist destinations.

This study has several limitations. First, the results are based on island destinations and there may be differences for other types of tourist destinations. Second, the results are based on cross-sectional data at a given point of time, and there might be inter-temporal changes in economic values that may affect their transferability, particularly if some of the climate change impacts are subject to specific outbreaks over the summer period as in the case of forest fires and heat waves. Thus, there is need of further research overcoming these limitations and bringing up more evidence and propose successful procedures that manage to reduce the transfer errors and improve the validity of benefit transfer.

Considering that climate change is a global phenomenon that affect all territories but in different ways, some regions may not experience such expected negative consequences of climate change in their local tourism economy. Thus, further research should reconsider the potential bias of this study towards the assessment of adaptation policies for negative impacts, by incorporating other positive effects as well as the game changers that may occur in several tourist destinations. Finally, a more integrated perspective between adaptation and mitigation programs may also be considered in future research avenues.

\section{Impact statement}

Fast adaptation is increasingly urgent in order to accommodate the tourism industry to a changing climate. In this vein, this study helps tourism practitioners and policy-makers of the seven studied islands destinations to identify which adaptation programs have greater potential to enhance tourists' perceived wellbeing and thus improve destinations' plans accordingly. It has also proven the validity of the benefits transfer method as an appropriate technique to transfer the willingness to pay of tourists to reward adaptation programs across destinations. The study opens a new opportunity for destination managers to utilise past information for the impact assessment of their climate-related adaptation plans, speeding up the implementation of climate action in more cost efficient terms. This research is even more valuable in the current climate emergency, since the tourism sector and the tourism academy have shown to lack strong capacity to provide the massive information requirements for climate change adaptation.

\section{Author contributions}

Conceptualization, C.J.L. and M.M.G.H.; methodology, Y.E.L.-G. and C.G.; data curation, C.G.G.; writing — original draft preparation, Y.E.L.G.; writing-review and editing, M.M.G.H. and C.G.; visualization, Y. E.L.-G.; supervision, C.J.L.; funding acquisition, all. All authors have read and agree to the published version of the manuscript.

\section{Funding}

Research for this paper has been supported by European Union's Horizon 2020 Research and Innovation programme under grant agreement No. 776661, project "SOCLIMPACT-DownScaling CLImate imPACTs and decarbonisation pathways in EU islands and enhancing socio-economic and non-market evaluation of Climate Change for Europe, for 2050 and beyond".

\section{Declaration of competing interest}

The authors declare no conflict of interest.

\section{Appendix A. Supplementary data}

Supplementary data to this article can be found online at https://doi. org/10.1016/j.tourman.2021.104471.

\section{References}

Amelung, B., \& Nicholls, S. (2014). Implications of climate change for tourism in Australia. Tourism Management, 41, 228-244.

Andreopoulos, D., \& Damigos, D. (2017). To transfer or not to transfer? Evidence from validity and reliability tests for international transfers of non-market adaptation benefits in river basins. Journal of Environmental Management, 185, 44-53.

Arabadzhyan, A., Figini, P., García, C., González, M. M., Lam-González, Y. E., \& León, C. J. (2020). Climate change, coastal tourism, and impact chains-a literature review. Current Issues in Tourism, 1-36.

Atzori, R., Fyall, A., \& Miller, G. (2018). Tourist responses to climate change: Potential impacts and adaptation in Florida's coastal destinations. Tourism Management, 69, $12-22$.

Bach, L., \& Burton, M. (2017). Proximity and animal welfare in the context of tourist interactions with habituated dolphins. Journal of Sustainable Tourism, 25(2), 181-197.

Bonnieux, F., Carpentier, A., \& Paoli, J. C. (2006). Preferences of residents and visitors regarding forest protection and management in Corsica: The Bonifatu case study. Revue Forestiere Française, 58(2), 167-180.

Boyle, K. J., \& Bergstrom, J. C. (1992). Benefit transfer studies: Myths, pragmatism, and idealism. Water Resources Research, 28(3), 657-663.

Brookshire, D. S., \& Neill, H. R. (1992). Benefit transfers: Conceptual and empirical issues. Water Resources Research, 28(3), 651-655.

Brouwer, R., Bliem, M., Getzner, M., Kerekes, S., Milton, S., Palarie, T., \& Wagtendonk, A. (2016). Valuation and transferability of the non-market benefits of river restoration in the Danube river basin using a choice experiment. Ecological Engineering, 87, 20-29.

Brouwer, R., Martin-Ortega, J., Dekker, T., Sardonini, L., Andreu, J., Kontogianni, A., \& Windle, J. (2015). Improving value transfer through socio-economic adjustments in a multicountry choice experiment of water conservation alternatives. The Australian Journal of Agricultural and Resource Economics, 59(3), 458-478.

Brouwer, R., \& Spaninks, F. A. (1999). The validity of environmental benefits transfer: Further empirical testing. Environmental and Resource Economics, 14(1), 95-117.

Buzinde, C. N., Manuel-Navarrete, D., Yoo, E. E., \& Morais, D. (2010). Tourists' perceptions in a climate of change: Eroding destinations. Annals of Tourism Research, 37(2), 333-354.

Cashman, A., Cumberbatch, J., \& Moore, W. (2012). The effects of climate change on tourism in small states: Evidence from the Barbados case. Tourism Review, 67(3), $17-29$.

Cavallaro, F., Ciari, F., Nocera, S., Prettenthaler, F., \& Scuttari, A. (2017). The impacts of climate change on tourist mobility in mountain areas. Journal of Sustainable Tourism, 25(8), 1063-1083.

Chaminuka, P., Groeneveld, R. A., Selomane, A. O., \& Van Ierland, E. C. (2012). Tourist preferences for ecotourism in rural communities adjacent to Kruger national park: A choice experiment approach. Tourism Management, 33(1), 168-176.

Choi, A. S., \& Ritchie, B. W. (2014). Willingness to pay for flying carbon neutral in Australia: An exploratory study of offsetter profiles. Journal of Sustainable Tourism, 22(8), 1236-1256.

Choi, A. S., Ritchie, B. W., Papandrea, F., \& Bennett, J. (2010). Economic valuation of cultural heritage sites: A choice modeling approach. Tourism Management, 31(2), 213-220.

Colombo, S., Calatrava-Requena, J., \& Hanley, N. (2007). Testing choice experiment for benefit transfer with preference heterogeneity. American Journal of Agricultural Economics, 89(1), 135-151.

Colombo, S., \& Hanley, N. (2008). How can we reduce the errors from benefits transfer? An investigation using the choice experiment method. Land Economics, 84(1), $128-147$.

Dumitras, D. E., Muresan, I. C., Jitea, I. M., Mihai, V. C., Balazs, S. E., \& Iancu, T. (2017). Assessing tourists' preferences for recreational trips in national and natural parks as a premise for long-term sustainable management plans. Sustainability, 9(9), Article 1596. 
Enríquez, A. R., \& Angel, B. B. (2020). Measuring the economic impact of climateinduced environmental changes on sun-and-beach tourism. Climatic Change, 160(2), 203-217.

Eymann, A., \& Ronning, G. (1997). Microeconometric models of tourists' destination choice. Regional Science and Urban Economics, 27(6), 735-761.

Faccioli, M., Font, A. R., \& Figuerola, C. M. T. (2015). Valuing the recreational benefits of wetland adaptation to climate change: A trade-off between species' abundance and diversity. Environmental Management, 55(3), 550-563.

Gómez-Martín, M. B., Armesto-López, X. A., Cors-Iglesias, M., \& Muñoz-Negrete, J. (2014). Adaptation strategies to climate change in the tourist sector: The case of coastal tourism in Spain. Tourism: An International Interdisciplinary Journal, 62(3), 293-308.

Gössling, S., Scott, D., Hall, C. M., Ceron, J. P., \& Dubois, G. (2012). Consumer behaviour and demand response of tourists to climate change. Annals of Tourism Research, 39 (1), 36-58.

Haidich, A. B. (2010). Meta-analysis in medical research. Hippokratia, 14(1), 29.

Hall, C. M., Gössling, S., \& Scott, D. (2012). Tourism and climate change: Impacts, adaptation and mitigation. Oxon: Routledge.

Hergesell, A., \& Dickinger, A. (2013). Environmentally friendly holiday transport mode choices among students: The role of price, time and convenience. Journal of Sustainable Tourism, 21(4), 596-613.

Heron, S. F., Eakin, C. M., Douvere, F., Anderson, K. L., Day, J. C., Geiger, E., \& Obura, D. O. (2017). Impacts of climate change on world heritage coral reefs: A first global scientific assessment.

Holden, A. (2016). Environment and tourism. Oxon: Routledge.

Hoyos, D. (2010). The state of the art of environmental valuation with discrete choice experiments. Ecological Economics, 69, 1595-1603.

Huybers, T. (2003). Domestic tourism destination choices-a choice modelling analysis. International Journal of Tourism Research, 5(6), 445-459.

Johnston, R. J., Boyle, K. J., Loureiro, M. L., Navrud, S., \& Rolfe, J. (2021). Guidance to enhance the validity and credibility of environmental benefit transfers. Environmental and Resource Economics, 1-50.

Johnston, R. J., \& Duke, J. M. (2010). Socioeconomic adjustments and choice experiment benefit function transfer: Evaluating the common wisdom. Resource and Energy Economics, 32(3), 421-438.

Johnston, R. J., Rolfe, J., Rosenberger, R. S., \& Brouwer, R. (2015). Benefit transfer of environmental and resource values. In The economics of non-market goods and resources (p. 14). Springer.

Johnston, R. J., \& Rosenberger, R. S. (2010). Methods, trends and controversies in contemporary benefit transfer. Journal of Economic Surveys, 24(3), 479-510.

Kaján, E., \& Saarinen, J. (2013). Tourism, climate change and adaptation: A review. Current Issues in Tourism, 16(2), 167-195.

Kaján, E., Tervo-Kankare, K., \& Saarinen, J. (2015). Cost of adaptation to climate change in tourism: Methodological challenges and trends for future studies in adaptation. Scandinavian Journal of Hospitality and Tourism, 15(3), 311-317.

Kaul, S., Boyle, K. J., Kuminoff, N. V., Parmeter, C. F., \& Pope, J. C. (2013). What can we learn from benefit transfer errors? Evidence from 20 years of research on convergent validity. Journal of Environmental Economics and Management, 66(1), 90-104.

Kemperman, A. (2021). A review of research into discrete choice experiments in tourism: Launching the annals of tourism research curated collection on discrete choice experiments in tourism. Annals of Tourism Research, 87, Article 103137.

Kim, D., \& Park, B. J. R. (2017). The moderating role of context in the effects of choice attributes on hotel choice: A discrete choice experiment. Tourism Management, 63, 439-451.

Kontogianni, A., Damigos, D., Tourkolias, C., Vousdoukas, M., Velegrakis, A., Zanou, B., Skourtos, M., et al. (2014). Eliciting beach users' willingness to pay for protecting European beaches from beachrock processes. Ocean \& Coastal Management, 98, 167-175. https://doi.org/10.1016/j.ocecoaman.2014.06.019

Kountouris, Y., \& Remoundou, K. (2011). Valuing the welfare cost of forest fires: A life satisfaction approach. Kyklos, 64(4), 556-578.

Krinsky, I., \& Robb, A. L. (1986). On approximating the statistical properties of elasticities. The Review of Economics and Statistics, 715-719.

Kristofersson, D., \& Navrud, S. (2005). Validity tests of benefit transfer-are we performing the wrong tests? Environmental and Resource Economics, 30(3), 279-286.

Kubo, T., Mieno, T., \& Kuriyama, K. (2019). Wildlife viewing: The impact of money-back guarantees. Tourism Management, 70, 49-55.

Lacher, R. G., Oh, C. O., Jodice, L. W., \& Norman, W. C. (2013). The role of heritage and cultural elements in coastal tourism destination preferences: A choice modeling-based analysis. Journal of Travel Research, 52(4), 534-546.

Landauer, M., Pröbstl, U., \& Haider, W. (2012). Managing cross-country skiing destinations under the conditions of climate change-Scenarios for destinations in Austria and Finland. Tourism Management, 33(4), 741-751.

Lee, C. K., Lee, J. H., Kim, T. K., \& Mjelde, J. W. (2010). Preferences and willingness to pay for bird-watching tour and interpretive services using a choice experiment. Journal of Sustainable Tourism, 18(5), 695-708.

León, C. J., de León, J., Araña, J. E., \& González, M. M. (2015). Tourists' preferences for congestion, residents' welfare and the ecosystems in a national park. Ecological Economics, 118, 21-29.

Liu, B., \& Pennington-Gray, L. (2017). Managing health-related crises in the cruise industry. Cruise Ship Tourism, 220-235. https://doi.org/10.1079/ 9781780646084.0220

Loomis, J. B. (1992). The evolution of a more rigorous approach to benefit transfer: Benefit function transfer. Water Resources Research, 28(3), 701-705.

Malpica-Cruz, L., Haider, W., Smith, N. S., Fernández-Lozada, S., \& Côté, I. M. (2017). Heterogeneous attitudes of tourists toward Lionfish in the Mexican Caribbean:
Implications for invasive species management. Frontiers in Marine Science, 4, Article 138.

Mariel, P., Hoyos, D., Meyerhoff, J., Czajkowski, M., Dekker, T., Glenk, K., \& Thiene, M. (2021). Environmental valuation with discrete choice experiments: Guidance on design, implementation and data analysis. Springer Nature.

Matthews, L., Scott, D., Andrey, J., Mahon, R., Trotman, A., Burrowes, R., \& Charles, A. (2021). Developing climate services for Caribbean tourism: A comparative analysis of climate push and pull influences using climate indices. Current Issues in Tourism, 24(11), 1576-1594.

Mavalankar, D., Puwar, T. I., Murtola, T. M., \& Vasan, S. S. (2009). Quantifying the impact of chikungunya and dengue on tourism revenues. WP series of the Indian Institute of Management Ahmedabad.

McClenachan, L., Matsuura, R., Shah, P., \& Dissanayake, S. (2018). Shifted baselines reduce willingness to pay for conservation. Frontiers in Marine Science, 5, 48.

Morley, C. L. (1994). Discrete choice analysis of the impact of tourism prices. Journal of Travel Research, 33(2), 8-14.

Morrison, M., Bennett, J., Blamey, R., \& Louviere, J. (2002). Choice modeling and tests of benefit transfer. American Journal of Agricultural Economics, 84(1), 161-170.

Naidoo, R., Beytell, P., Malherbe, A., Middleton, A., Perche, J., \& Muntifering, J. R. (2021). Heterogeneous consumer preferences for local community involvement in nature-based tourism drive triple-bottom-line gains. Conservation Science and Practice, Article e425.

Nilsson, J. H., \& Gössling, S. (2013). Tourist responses to extreme environmental events: The case of Baltic Sea algal blooms. Tourism Planning \& Development, 10(1), 32-44.

Nunes, P. A., Loureiro, M. L., Piñol, L., Sastre, S., Voltaire, L., \& Canepa, A. (2015). Analyzing beach recreationists' preferences for the reduction of jellyfish blooms: Economic results from a stated-choice experiment in Catalonia, Spain. PLoS One, 10 (6), Article e0126681.

Olmsted, P., Honey-Rosés, J., Satterfield, T., \& Chan, K. M. (2020). Leveraging support for conservation from ecotourists: Can relational values play a role? Journal of Sustainable Tourism, 28(3), 497-514.

Otrachshenko, V., \& Nunes, L. C. (2019). Fire takes no vacation: Impact of fires on Tourism. NOVA Working Papers. \#632.

Panzer, J., \& Saavedra, P. (2016). The short-term economic costs of Zika in Latin America and the Caribbean. Washington: World Bank.

Poe, G. L., Severance-Lossin, E. K., \& Welsh, M. P. (1994). Measuring the difference $(\mathrm{X}-\mathrm{Y})$ of simulated distributions: A convolutions approach. American Journal of Agricultural Economics, 76(4), 904-915.

Poloczanska, E. S., Limpus, C. J., \& Hays, G. C. (2009). Vulnerability of marine turtles to climate change. Advances in Marine Biology, 56, 151-211.

Raybould, M., et al. (2013). Beach and surf tourism and recreation in Australia: Vulnerability and adaptation. Queensland: Bond University.

Reimann, L., Vafeidis, A. T., Brown, S., Hinkel, J., \& Tol, R. S. (2018). Mediterranean UNESCO World Heritage at risk from coastal flooding and erosion due to sea-level rise. Nature Communications, 9(1), 1-11.

Rolfe, J., \& Windle, J. (2012). Distance decay functions for iconic assets: Assessing national values to protect the health of the great barrier reef in Australia. Environmental and Resource Economics, 53(3), 347-365.

Rosenberger, R. S. (2015). Benefit transfer validity and reliability. In Benefit transfer of environmental and resource values (pp. 307-326). Dordrecht: Springer.

Rosenberger, R. S., \& Loomis, J. B. (2003). Benefit transfer. In A primer on nonmarket valuation (pp. 445-482). Dordrecht: Springer.

Rosenberger, R. S., \& Stanley, T. D. (2006). Measurement, generalization, and publication: Sources of error in benefit transfers and their management. Ecological Economics, 60(2), 372-378.

Rulleau, B., \& Rey-Valette, H. (2013). Valuing the benefits of beach protection measures in the face of climate change: A French case-study. Journal of Environmental Economics and Policy, 2(2), 133-147. https://doi.org/10.1080/ 21606544.2013.776213

Rutty, M., \& Scott, D. (2010). Will the Mediterranean become "too hot" for tourism? A reassessment. Tourism and Hospitality Planning \& Development, 7(3), 267-281.

Rutty, M., Scott, D., Matthews, L., Burrowes, R., Trotman, A., Mahon, R., \& Charles, A. (2020). An inter-comparison of the holiday climate index (HCI: Beach) and the tourism climate index (TCI) to explain Canadian tourism arrivals to the Caribbean. Atmosphere, 11(4), Article 412.

Ryan, S. J., Carlson, C. J., Mordecai, E. A., \& Johnson, L. R. (2019). Global expansion and redistribution of Aedes-borne virus transmission risk with climate change. PLoS Neglected Tropical Diseases, 13(3), Article e0007213. https://doi.org/10.1371/ journal.pntd.0007213

Schuhmann, P. W., Skeete, R., Waite, R., Lorde, T., Bangwayo-Skeete, P., Oxenford, H. A., \& Spencer, F. (2019). Visitors' willingness to pay marine conservation fees in Barbados. Tourism Management, 71, 315-326.

Scott, D. (2021). Sustainable tourism and the grand challenge of climate change. Sustainability, 13(4), Article 1966.

Scott, D., \& Becken, S. (2010). Adapting to climate change and climate policy: Progress, problems and potentials. Journal of Sustainable Tourism, 18(3), 283-295.

Scott, D., Dawson, J., \& Jones, B. (2008). Climate change vulnerability of the US Northeast winter recreation-tourism sector. Mitigation and Adaptation Strategies for Global Change, 13(5), 577-596.

Scott, D., Hall, C. M., \& Gössling, S. (2012a). Tourism and climate change. Impacts, adaptation and mitigation. Oxon: Routledge.

Scott, D., Hall, C. M., \& Gössling, S. (2019). Global tourism vulnerability to climate change. Annals of Tourism Research, 77, 49-61.

Scott, D., \& Lemieux, C. (2012). The vulnerability of tourism to climate change. In The Routledge handbook of tourism and the environment (pp. 263-279). Routledge. 
Scott, D., Simpson, M. C., \& Sim, R. (2012b). The vulnerability of Caribbean coastal tourism to scenarios of climate change related sea level rise. Journal of Sustainable Tourism, 20(6), 883-898.

Scuttari, A., Orsi, F., \& Bassani, R. (2019). Assessing the tourism-traffic paradox in mountain destinations. A stated preference survey on the Dolomites' passes (Italy). Journal of Sustainable Tourism, 27(2), 241-257.

Seekamp, E., Jurjonas, M., \& Bitsura-Meszaros, K. (2019). Influences on coastal tourism demand and substitution behaviors from climate change impacts and hazard recovery responses. Journal of Sustainable Tourism, 27(5), 629-648.

Smith, V. K. (1992). On separating defensible benefit transfers from "smoke and mirrors". Water Resources Research, 28(3), 685-694.

Susanto, J., Zheng, X., Liu, Y., \& Wang, C. (2020). The impacts of climate variables and climate-related extreme events on island country's tourism: Evidence from Indonesia. Journal of Cleaner Production, 276, Article 124204.

Swait, J., \& Louviere, J. (1993). The role of the scale parameter in the estimation and comparison of multinomial logit models. Journal of Marketing Research, 30(3), 305-314.

Tang, Z. (2015). An integrated approach to evaluating the coupling coordination between tourism and the environment. Tourism Management, 46, 11-19.

Thapa, B., Cahyanto, I., Holland, S. M., \& Absher, J. D. (2013). Wildfires and tourist behaviors in Florida. Tourism Management, 36, 284-292.

Tseng, W. W. C., Hsu, S. H., \& Chen, C. C. (2015). Estimating the willingness to pay to protect coral reefs from potential damage caused by climate change- -the evidence from Taiwan. Marine Pollution Bulletin, 101(2), 556-565.

Verkoeyen, S., \& Nepal, S. K. (2019). Understanding scuba divers' response to coral bleaching: An application of Protection Motivation Theory. Journal of Environmental Management, 231, 869-877.

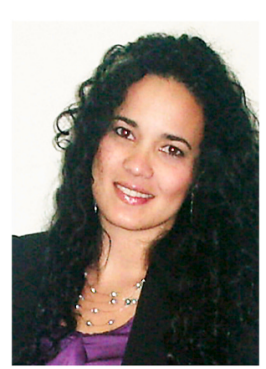

Yen E. Lam González holds a $\mathrm{PhD}$ in Economics from the University of Las Palmas de Gran Canaria (ULPGC), and a bachelor in Economics (2005) and MBA (2008) from University of Havana, Cuba. She is also Master in Integral Development of Tourism Destinations (2012) from the University of Las Palmas de Gran Canaria (ULPGC), Spain. She teaches at University of Las Palmas de Gran Canaria (ULPGC), the Autonomous University of Chile, and the University of Cartagena (Colombia). She is postdoctoral researcher and responsible of the Division of Climate Change at the UNESCO Chair in Tourism Planning and Sustainable Development ULPGC.

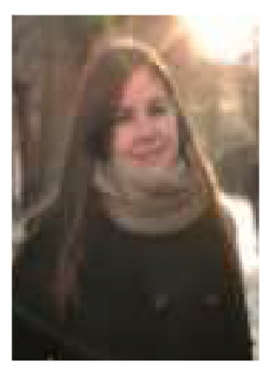

Carmen García holds a $\mathrm{PhD}$ in Economics from the European University Institute (Italy). She studied the Bachelor degree in Economics at the University of Las Palmas de Gran Canaria (Spain), and undertook the Master in Economic Analysis at the University Carlos III de Madrid (Spain). At the moment, she is professor at the Department of Economic Analysis of the University of Las Palmas de Gran Canaria (ULPGC).

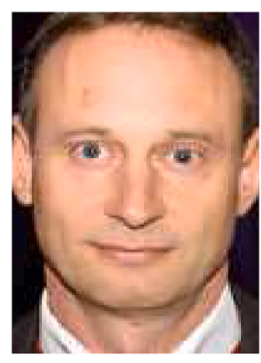

Matías González is $\mathrm{PhD}$ in Economics from the University of Las Palmas de Gran Canaria (ULPGC) and Bachelor of Economics from the University of La Laguna, Tenerife. He teaches at the Department of Economic Analysis. He is Managing Director at the UNESCO Chair in Tourism Planning and Sustainable Development ULPGC. He has been the principal investigator of several national and international projects related to Environment and Tourism. He is specialized in environmental economics, sustainable tourism, international cooperation and the economics of tourism.

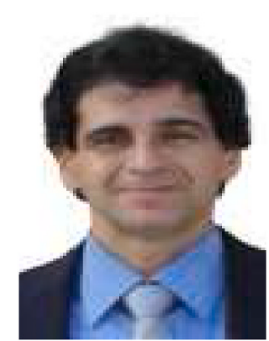

Carmelo J. León González is a $\mathrm{PhD}$ in Economics from the University of Las Palmas de Gran Canaria (ULPGC) and Bachelor of Economics from the University of La Laguna, Tenerife. $\mathrm{He}$ is also Master in Economics and Diploma in Economics from the University of Manchester. He teaches at the Department of Economic Analysis since 1989. He is Director of the Research Group Ecomas (Economy, Environment, Sustainability and Tourism), Director of the Institute of Tourism and Sustainable Economic Development (Tides) and the UNESCO Chair in Tourism Planning and Sustainable Development ULPGC. He is specialized in environmental economics, the valuation of environmental goods, the economics of tourism, economy aquaculture and natural resources. He has spoken at numerous conferences nationally and internationally and has written more than 70 scholarly articles, books and book s chapters. Heading up TIDES his mission is to bring the fledgling center into the top ten tourism institutes in the world via a multitude of interdisciplinary research initiatives. 